\title{
A TWO-DIMENSIONAL STUDY ON THE WEAK-MOTION SEISMIC RESPONSE OF THE ABURRA VALLEY, MEDELLÍN, COLOMBIA
}

\author{
Brian M. Adams ${ }^{1}$ and Juan Diego Jaramillo ${ }^{2}$
}

\begin{abstract}
A two-dimensional elastic finite-element method is used to investigate the weak-motion seismic response of the Aburrá Valley of Medellín, Colombia. A vertically propagating antiplane SH Ricker wavelet is used to study the response of the valley for frequencies up to $5 \mathrm{~Hz}$. The Aburrá Valley is very large and geologically diverse. The $\sim 1200$-metre-deep and $\sim 15$ kilometre-wide valley is covered by a variable layer of soft soils averaging some 30 metres deep. The soils are mainly residual, alluvial or debris-flow deposits. The valley also contains a network of 24 strong-motion seismic recorders. A 49,900-element mesh of a cross-sectional model through the southern end of Medellín is analysed using the finite-element software package, Archimedes. The results are presented in both time and frequency domains. A similar one-dimensional finite-element method is used for comparison. It is found that while amplification often occurs at frequencies defined by a one-dimensional analysis, the level of amplification is often highly dependent on multi-dimensional effects. Local irregularities in the stratigraphy and topography at some sites have a significant effect on the seismic response. Site response may also be influenced strongly by sub-valley structures up to a few kilometres across, yet the influence of the valley as a whole is small. Poor correlation between modelling results and recorded data is probably due to a lack of site-specific detail within the model, and the limiting two-dimensional nature of the analysis.
\end{abstract}

\subsection{INTRODUCTION}

The seismic site response of non-uniform near-surface geology such as sediment-filled basins and topographic ridges and valleys is of great interest to a geologically diverse and tectonically active country like New Zealand. Such complex geology often leads to serious multi-dimensional amplification effects such as focussing, basin resonance, and edge effects. These amplifications cannot be modelled nor predicted with simple one-dimensional analyses as is commonly used in engineering design.

The South American country of Colombia also fits the geologically diverse and tectonically active description very well, and contains many sites of interest. One of these is the city of Medellín in the Aburrá Valley, which in addition to complex near-surface geology, contains the largest local network of accelerographs in South America. Anomalously high levels of ground motion at several of these accelerograph stations indicate that the seismic response is probably dominated by multi-dimensional amplifications.
In this study two-dimensional elastic finite-element modelling is used to investigate the seismic response across the width of the Aburrá Valley. A similar method was used by the authors in a study of the much smaller Wellington-Hutt Valley basin in New Zealand (Adams et al., 2000). An attempt is made to determine if two-dimensional effects are likely to dominate the seismic response of the valley as a whole and to look for areas where multi-dimensional focussing or edge effects might generate locally high amplifications. The results are compared with those obtained from recorded weak motions at some of the accelerograph sites.

\subsection{PHYSICAL SETTING}

Colombia is located in the north-west corner of the South American continent near the boundary of the Nazca, Caribbean and South American tectonic plates (Figure 1), with a land area of $1,141,748 \mathrm{~km}^{2}$ and a population of 37.5 million. The western half of the country is mountainous, containing three parallel branching cordillera (mountain ranges) of the Northern Andes, while the eastern territory is extensive lowland

\footnotetext{
URS New Zealand Limited, PO Box 4479, Christchurch, New Zealand, Brian_Adams@ URSCorp.com (Member).

Ingeneria Civil, Universidad EAFIT, Medellin, Colombia, jjarami@eafit.edu.co
} 
jungle of the Orinoco and Amazon basins. With such diverse and rugged geography, Colombia is a land frequented by natural disasters, with many historical episodes of flooding, hurricanes, earthquakes, volcanic eruptions, tsunami and avalanches.

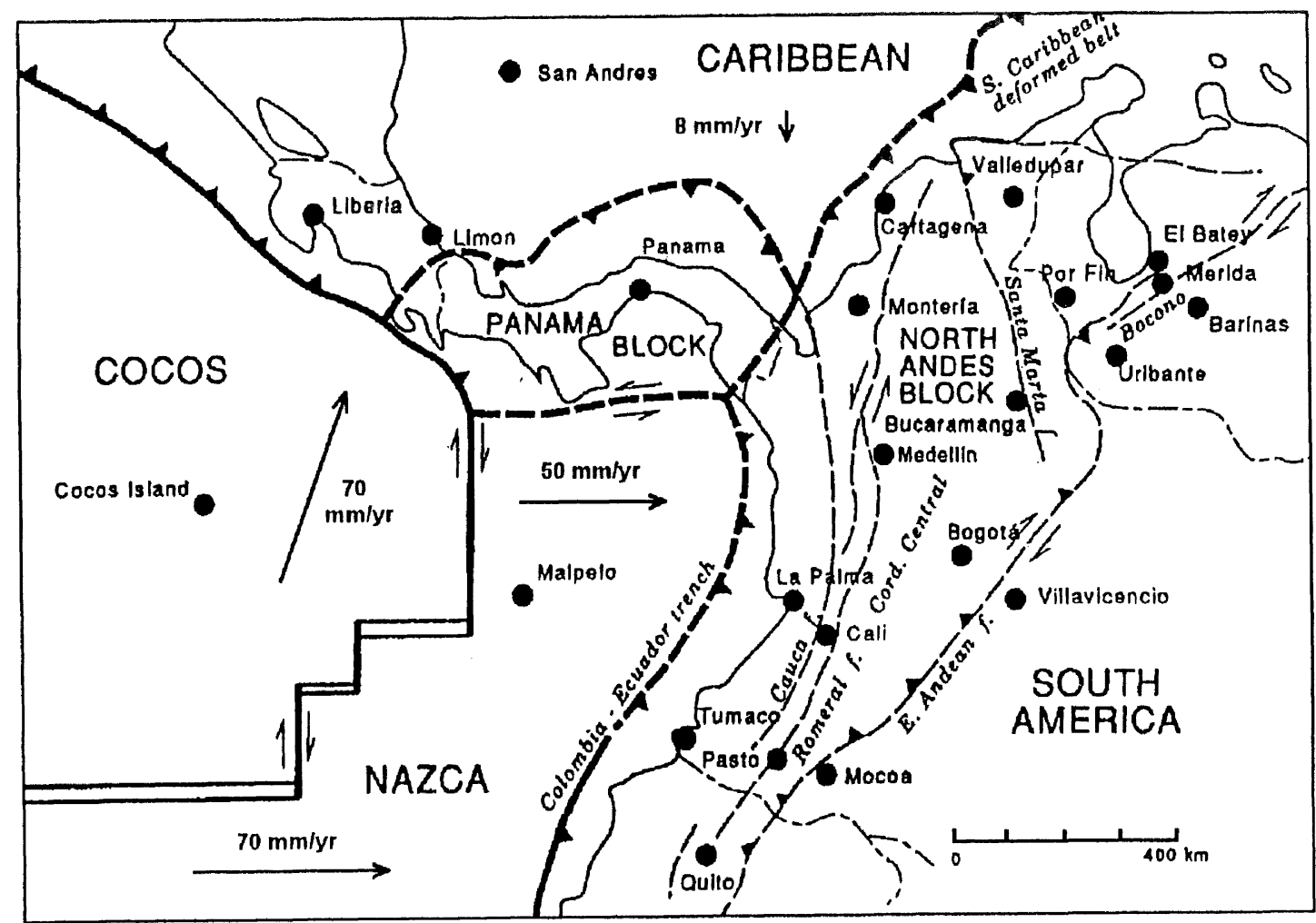

Figure 1. Tectonic plate interactions in north-west South America showing directions and rates of plate movements relative to the South American plate (after Kellogg and Dixon, 1990). The North Andes Block of western Colombia is in a tectonic regime of compression, uplift and sinistral strike-slip movement.

Medellín is Colombia's second largest city and the capital of the Department of Antioquia. It has a population of 1.8 million (June 1995), and an urban area of $110 \mathrm{~km}^{2}$ spectacularly located in the deep Aburrá Valley (Figure 2), a 1200 metre deep depression in the northern part of the Central Cordillera. The Aburrá Valley drains north to northeast for $200 \mathrm{~km}$ into the Cauca River and then to the Carribean Sea some $500 \mathrm{~km}$ away. Medellín is located at an altitude of 1500 metres, while the surrounding rolling countryside of the cordillera lies at an altitude between 2600 and 2800 metres. The central business district (CBD) of Medellín (Figure 3) is located in the bottom of the valley. The urban area extends to a length of $25 \mathrm{~km}$ and a width of $5-10 \mathrm{~km}$.

A large percentage of the valley is covered by residential, industrial and commercial buildings. There is very little completely flat land within the city, with the sides gently sloping up from the river, and steepening toward the crest of the bordering hills. The $\mathrm{CBD}$ is built on alluvial deposits from the Medellin River and the Santa Helena Stream (Figure 3), where there is a cluster of buildings in the 20-40 storey range Much of the population lives in multi-storey apartment buildings up to 20 stories in height, but generally in the 4-8 storey range. Many also live in single-or doublestorey single-family dwellings. Higher up the slopes, and in the northern end of the valley, the construction is of a much poorer standard, and often of unreinforced hollow-core masonry.

\subsection{THE MEDELLÍN INSTRUMENTATION AND MICROZONATION PROJECT}

Recent damaging earthquake in Medellín, in November 1979 and October 1992, sparked the start of a comprehensive study of earthquake risk in the city. In 1993, a preliminary seismic risk study by the Universidad EAFIT (Velásquez and Jaramillo, 1993; Hincapié et al., 1993; Jaramillo and Ortega, 1993) found that a re-occurrence of the 1979 event would cost the city an estimated \$US300 million. It was noted that the damage distribution from the most recent earthquakes had been very erratic and concentrated in certain zones, indicating a very non-uniform shaking pattern. The observations called to the need for a detailed study of the area to aid in the safe and efficient seismic design of the city and its infrastructure. 


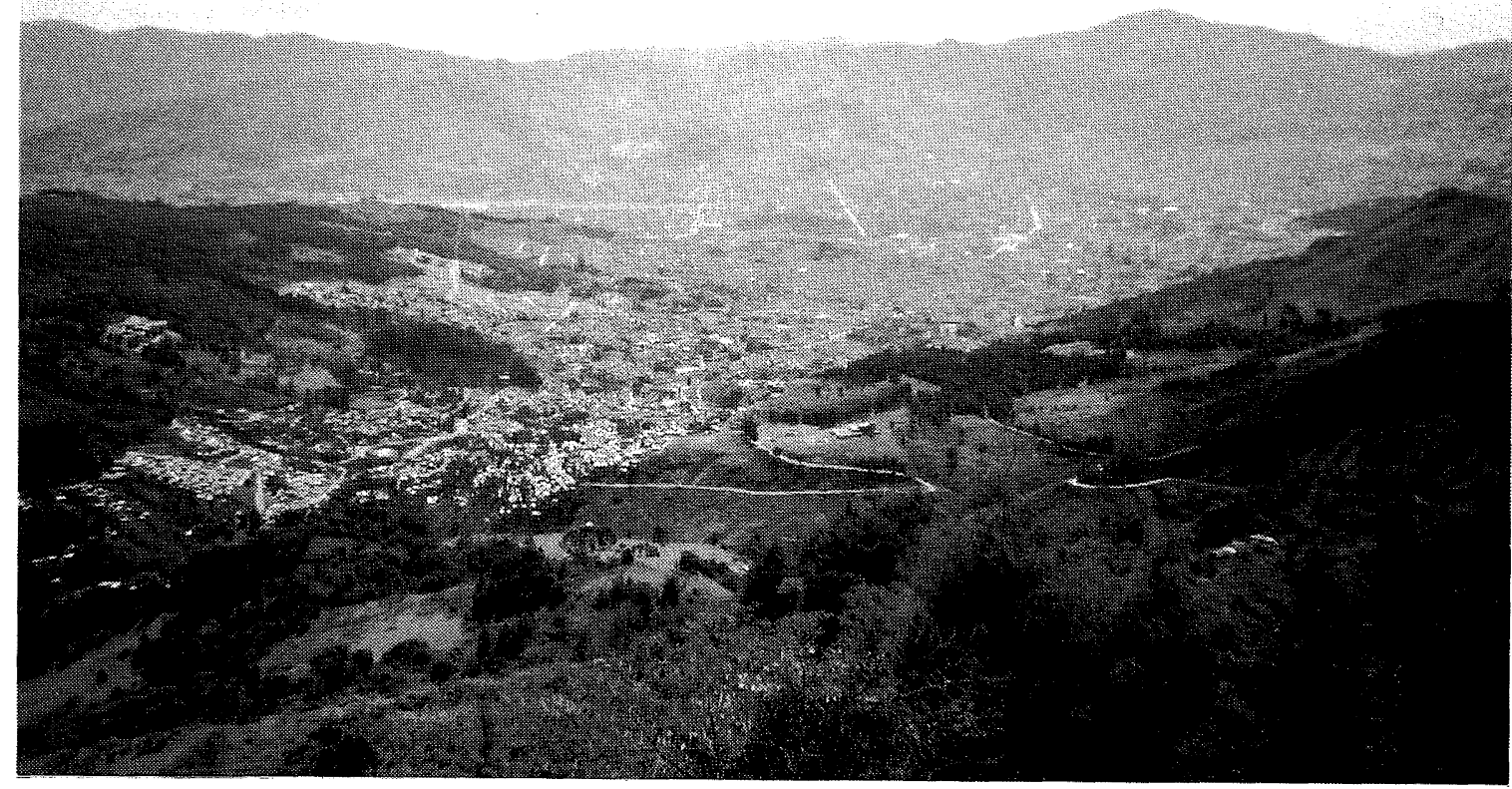

Figure 2. Central Medellín lies at the bottom of the deep Aburrá Valley, here viewed from high above Santa Helena Stream.

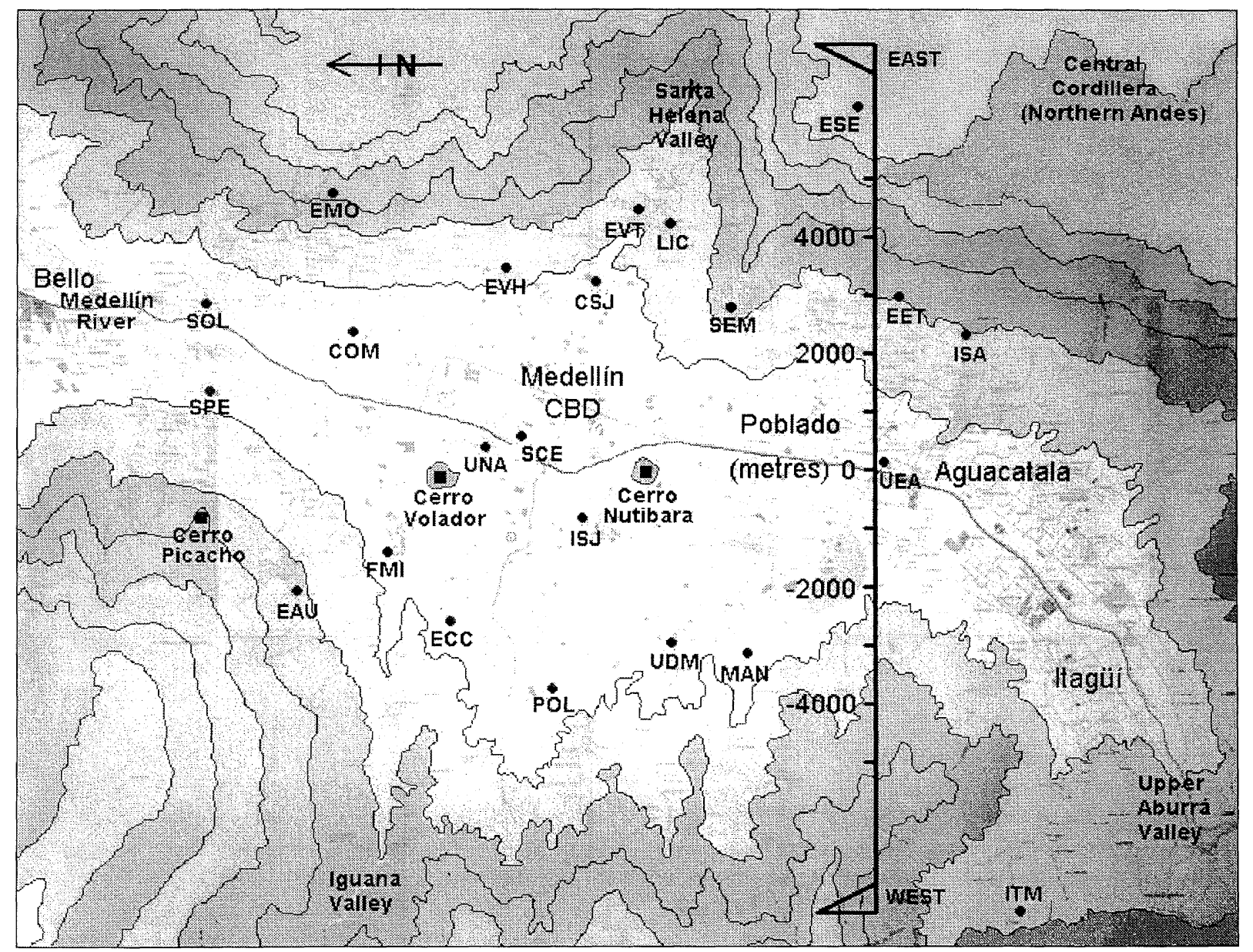

Figure 3. Topographic map of the Aburrá Valley at Medellín with a contour interval of 200 m. The Medellín River runs north from right to left. The location of the cross-section taken through EAFIT University (near $U E A)$ is plotted along with the 22 accelerograph station sites. 
An interdisciplinary group was formed called the Groupo de Sismología de Medellín (GSM). This included the Universidad EAFIT, the Faculty of Mining at the Universidad Nacional de Colombia, INGEOMINAS (National Institute of Geo-Sciences, Mining and Chemistry) and consulting engineers Integrál, S.A. The GSM was given the Instrumentation and Microzonation Project by SIMPAD (System for the Prevention and Attention of Disasters in Medellín) which had been appointed by the Private Secretary of the Medellín Municipal. The results of the Instrumentation and Microzoning Project (GSM, 1997, 1999) include: A re-evaluation of the seismic risk for the city; the installation of a 24 instrument-strong accelerograph network and the subsequent capturing of a large amount of weak motion data; geology and geomorphology maps of the city to a scale of $1: 10,000$; a three-dimensional geotechnical model of the subsurface geology down to bedrock; and a seismic microzonation map of the city to a scale of $1: 10,000$.

\subsection{SEISMIC RISK TO THE CITY OF MEDELLIN}

Seismic activity in Colombia consists both of shallow and deep events along the various subduction interfaces, and shallow crustal events within the tectonic plates shown in Figure 1. Historically, Medellín has received only low to moderate strength shaking from both nearby small magnitude earthquakes, and many large-magnitude earthquakes several hundred kilometres distant and/or deep. Since 1730 there have been reports of 39 earthquakes felt in Medellín with an intensity of MM III or more (GSM, 1999). The most recent of these was the $M_{L} 6.2$ Armenia earthquake on the 25th Juanary 1999 in the coffee growing region of Quindio (Restrepo and Cowan, 2000; Escallón and Alarcón, 2000). This earthquake was centred on the Romeral Fault (see Figure 1) $200 \mathrm{~km}$ south of Medellín. This $600 \mathrm{~km}-\mathrm{long}$ north-south trending Romeral Fault System of the Central Cordillera has been the source of several of the Colombia's most important earthquakes, including those in Popayán (1983), Páez (1994) and Armenia (1999). Its northern branches lie within $15 \mathrm{~km}$ of Medellín, yet in recorded history none of these have produced earthquakes with magnitude greater than $\mathrm{M}_{\mathrm{S}}$ 5.0.

The most damaging earthquakes in Medellín in recent history are those of November 1979 and October 1992, during which the maximum acceleration on the rock reached 0.03 and $0.015 \mathrm{~g}$ respectively. These were large earthquakes yet they both originated some distance away; the 1979 event $\left(M_{S} 6.7\right)$ from the Viejo Caldas Seismic Zone 100-200 km to the south, and the 1992 event $\left(M_{S} 7.2\right)$ from the Murindó Fault $160 \mathrm{~km}$ to the northwest causing an estimated \$US 11 million loss in Medellín (Fairbaiz et al., 2000).
Detailed probabilistic analyses have estimated peak ground accelerations for Medellín as a function of return period. At a $90 \%$ confidence level, a PGA of $0.03 \mathrm{~g}$ is expected for an earthquake with a return period of 10 years, while a PGA of $0.15 \mathrm{~g}$ is expected for a 475-year earthquake. A worst-case scenario earthquake - a rupture on nearby branches of the Romeral Fault - could generate accelerations in the order of $0.4 \mathrm{~g}$ (GSM, 1997).

\subsection{ACCELEROGRAPH NETWORK DATA}

Medellín is now the second most well instrumented city in Latin America, after Mexico City. The Medellín Accelerograph Network, R.A.M. (Red Accelerographica de Medellín), consists of 24 strong motion instruments recording motions at 22 different sites across the valley (see Figure 3 ). All but one of the instrument sites are located at one of 32 boreholes drilled as part of the microzonation study. The other station, ESE, is positioned on outcropping rock on the eastern hill high above EAFIT University. Two of the sites (EET and POL) contain two instruments, one on the surface and one at depth. Some 27 earthquakes have been recorded between November 1996 and November 1999. On average, about 15 of the 24 instruments will be triggered during a small event. The records are processed and archived at the R.A.M. Processing Centre within the Department of Civil Engineering at EAFIT University.

\subsection{ABURRÁ VALLEY GEOLOGY}

There are several different types of basement rocks in the area, all of which are plutonic or metamorphic. The metamorphic rocks (gneiss and amphibolite) are the oldest and date back to the Cretaceous or possibly the lower Paleozoic, while the igneous stocks of dunite, gabbro, grano-diorite and diorite date back to the Cretaceous and have intruded into the gneiss and amphibolites. There are several theories as to the origin of the deep Aburrá valley (see GSM, 1997 for a comprehensive compilation of various hypotheses). The idea that the valley may be a graben structure is most unlikely due to the compressive regime existing within the North Andes block (D. Rondón, pers. comm.). Almost certainly it is influenced by the northsouth trending Romeral and Cauca fault systems of the Central Cordillera and Cauca Valley, and possibly some form of extensional strike-slip duplex.

A variable depth of soft material exists above the basement rock within the valley. This soft covering may consist of one or any combination of residual (weathered in-place) soils, weathered non-consolidated debris flow deposits and alluvial deposits dating back to the quaternary. These soft units are on average 30 metres thick. The geomorphology of the land is in most cases highly correlated with the local geology. The steepest and most elevated parts of the city generally 
coincide with basement rock with a residual soil covering, such as the residual soil profile of dunite shown in Figure 4. The slopes characterised by moderate inclinations $\left(\sim 10-30^{\circ}\right)$ and elevations are often deposits of debris flows originating from higher and steeper slopes, while the flattest and lowest parts of the city are generally on alluvial deposits.

Debris flows mainly from the residual soils of dunite, amphibolite and Altavista Stock (gabbro-diorite) have created extensive areas of moderately sloping land at mid to low altitudes. They have been classified into four groups based mainly on the degree of weathering and location. The oldest flows (Qfm) are found both high on the slopes, and at the bottom of the stratigraphic column. Above these and lower down the slopes the more recent flows are found in order of occurrence (Qff and Qfr respectively). Debris flow deposits are characteristically very rubbly with large blocks surrounded by a fine matrix (Figure 5). On the south-eastern flank above Universidad EAFIT, a significant portion of the oldest debris flows (Qfm) have undergone enough weathering to be able to be classified as a soil derived from debris flows (Qfs).

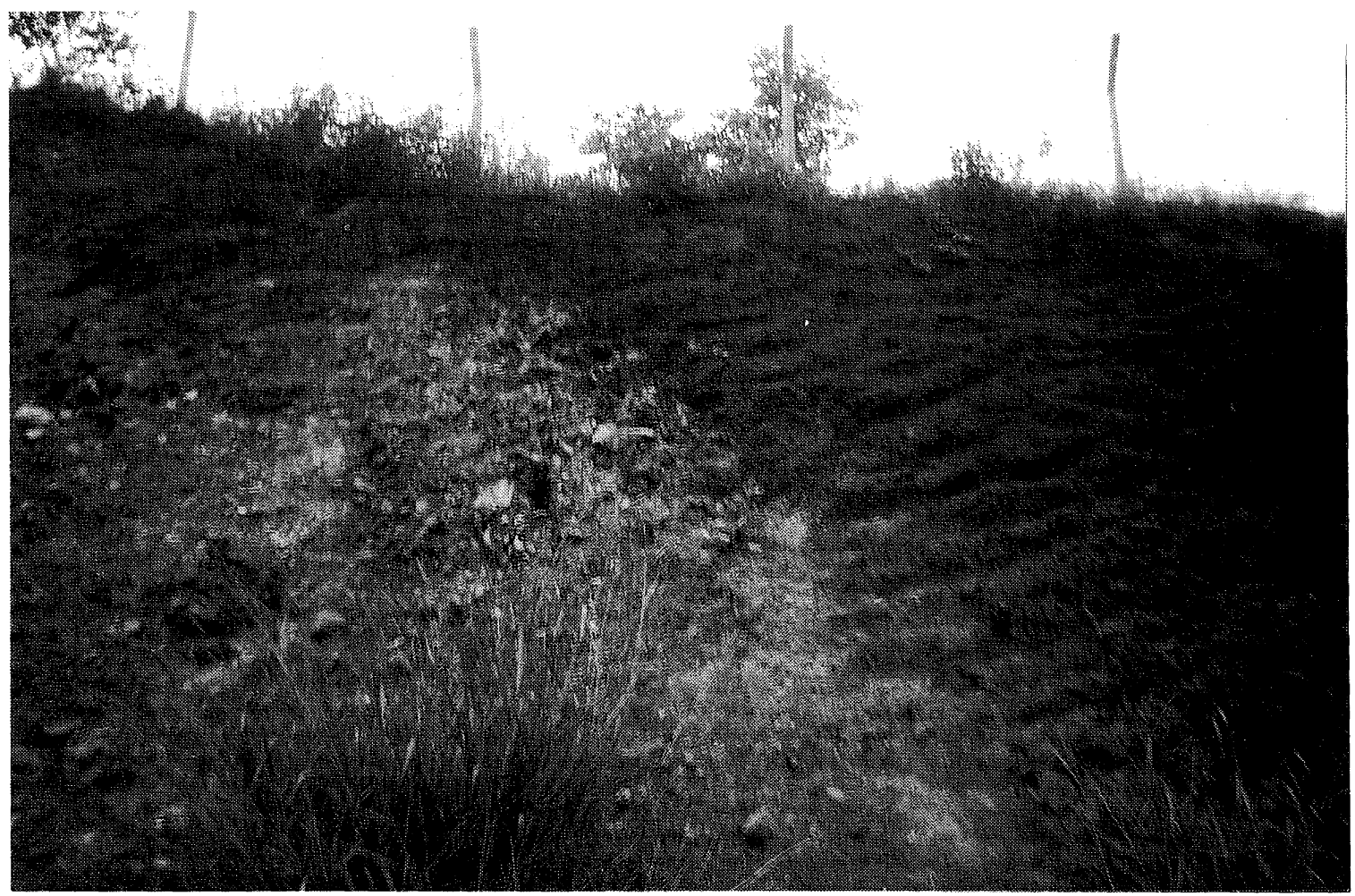

Figure 4. A residual soil profile at a road cutting on the north-eastern flank of the valley. An interface between highly weathered dunite soil and more competent rock can be seen sloping down to the right. The fence posts at the top of the photograph are approximately $2 \mathrm{~m}$ tall.

The Medellin river and other smaller streams (in particular the Santa Helena, Iguaná and those in the south-west) have deposited a significant amount of alluvium (Qal) in the central and lowest part of the valley. As a result, the south-west sector contains the most extensive area of alluvial deposit between the debris flows and the Medellín River, some 1-2 km wide. Topography on the alluvial deposits is smooth and the slope is generally less than $5 \%$. The depth of this deposit has been found to be highly variable (between 3 and 200 metres). In the lower reaches of many of the side creeks, unsorted flood deposits cover small areas. In several places, local mass-movements (up to $0.5 \mathrm{~km}^{2}$ in size) of various units have produced colluvial deposits of various types, while many small pockets of artificial fill (Qll) have been placed around the city, mainly as a result of construction operations.
Several outcropping hills form noticeable irregularities in the topography of the debris flows and alluvial deposits. The most interesting of these are a line of outcropping amphibolite peaks running in the NNESSW orientation on western side of the valley. These are the prominent Cerro Nutibarra, Cerro Volador and Cerro El Picacho shown in Figure 3). Along with other less prominent outcrops of diorite, gneiss, dunite and gabbro, they indicate that the basement is not necessarily very smooth or uniform. It is likely that beneath both the debris flows and alluvial deposits that cover the majority of the urbanised part of the valley the basement is highly irregular and capable of producing all manner of focussing and wave-path effects. 


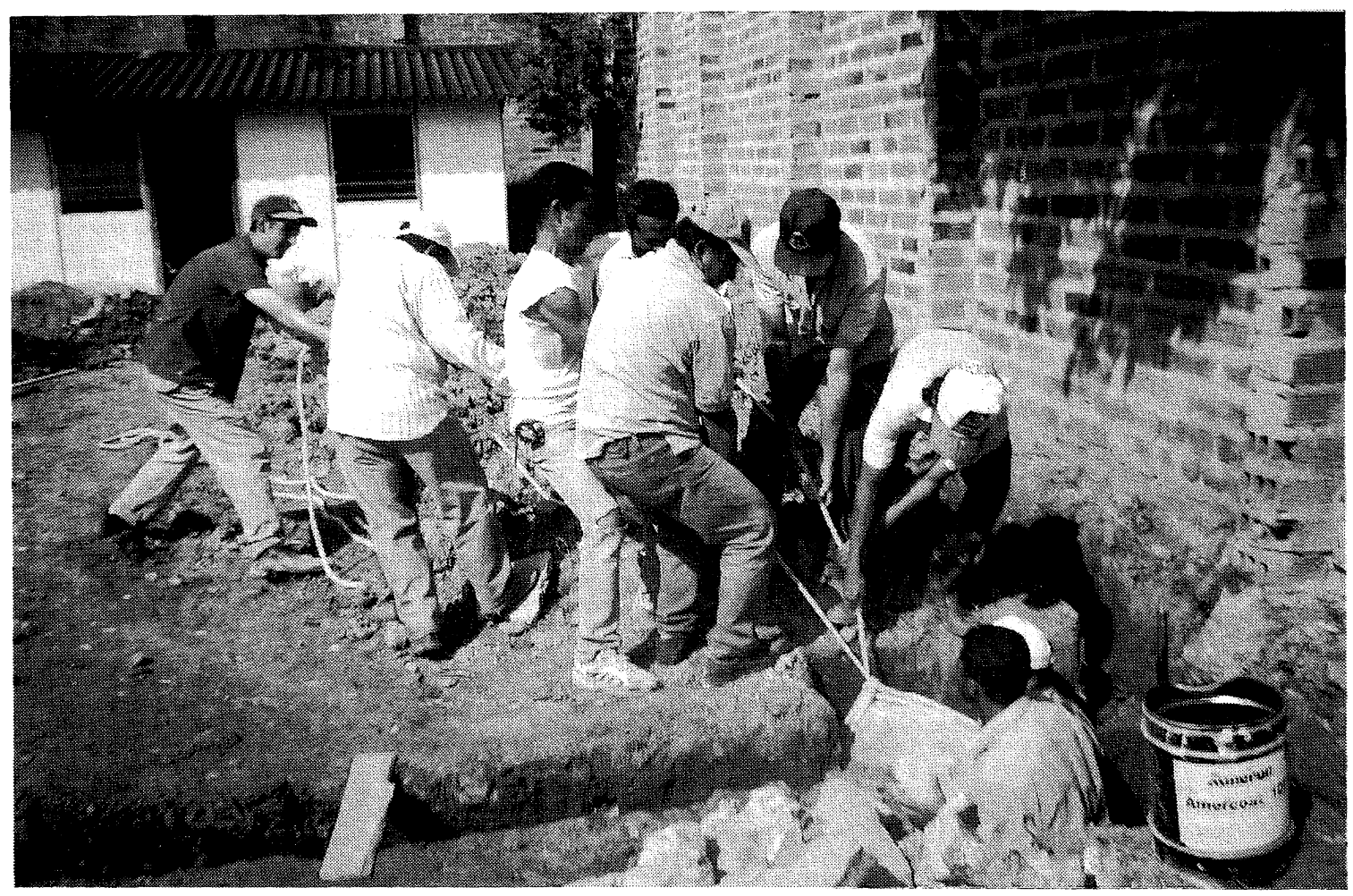

Figure 5. A construction gang removes a large boulder from an excavation into rubbly debris-flow deposits (Qfm) near accelerograph station POL.

\subsection{GEOLOGICAL AND GEOTECHNICAL DATA}

The current database consists of information from a total of 940 boreholes drilled between 1955 and 1998, 32 of which were drilled as part of the most recent microzonation study. These 32 boreholes were located so as to obtain a representative sample of the different geology and geomorphology within the valley. They have an average depth of 29 metres, the deepest (48 metres) being located at station SEM and the shallowest (16 metres) at UNA (see Figure 5). Borehole tests at the microzonation study sites and laboratory testing of intact samples have provided a large amount of geophysical and geotechnical data in addition to the stratigraphic information. This includes both static properties (density, plasticity, water content, grainsize distribution, penetration [SPT] values) and dynamic properties ( $S$ - and $P$ - wave velocities, $V_{S} \&$ $V_{P}$, shear modulus, $G$, fraction of critical damping, $\zeta$, and the variation of $G$ and $\zeta$ with respect to strain from cyclic triaxial tests). These results have been compiled alongside surface geology information, and integrated with a geographical information system to produce a three-dimensional geological and geotechnical database of the city.

\subsection{METHOD OF ANALYSIS}

One- and two-dimensional finite-element methods are used to investigate the elastic seismic response of a typical cross-section through the Aburrá Valley. Fourier spectral ratios (Borcherdt, 1970) calculated by both these methods are then compared against those from recorded data at three different stations.

\subsection{ABURRÁ VALLEY CROSS-SECTION AND TWO-DIMENSIONAL MODEL}

An east-west cross-section has been taken though the southern end of the city (Figure 6) almost directly through the Universidad EAFIT. Here the valley is narrower and more two-dimensional than in the CBD, where two major side streams (Iguaná and Santa Helena), several hills (eg. Cerros Nutibara and Volador) and a leading ridge from the south-east dominate the topography. The geometry of the crosssection was taken directly from data in the 3-D geotechnical-geological model, geological maps and topographic maps (GSM, 1997, 1999) for a line with an orientation exactly east-west along the latitude $6.204^{\circ}$ north plotted on Figure 3 . 


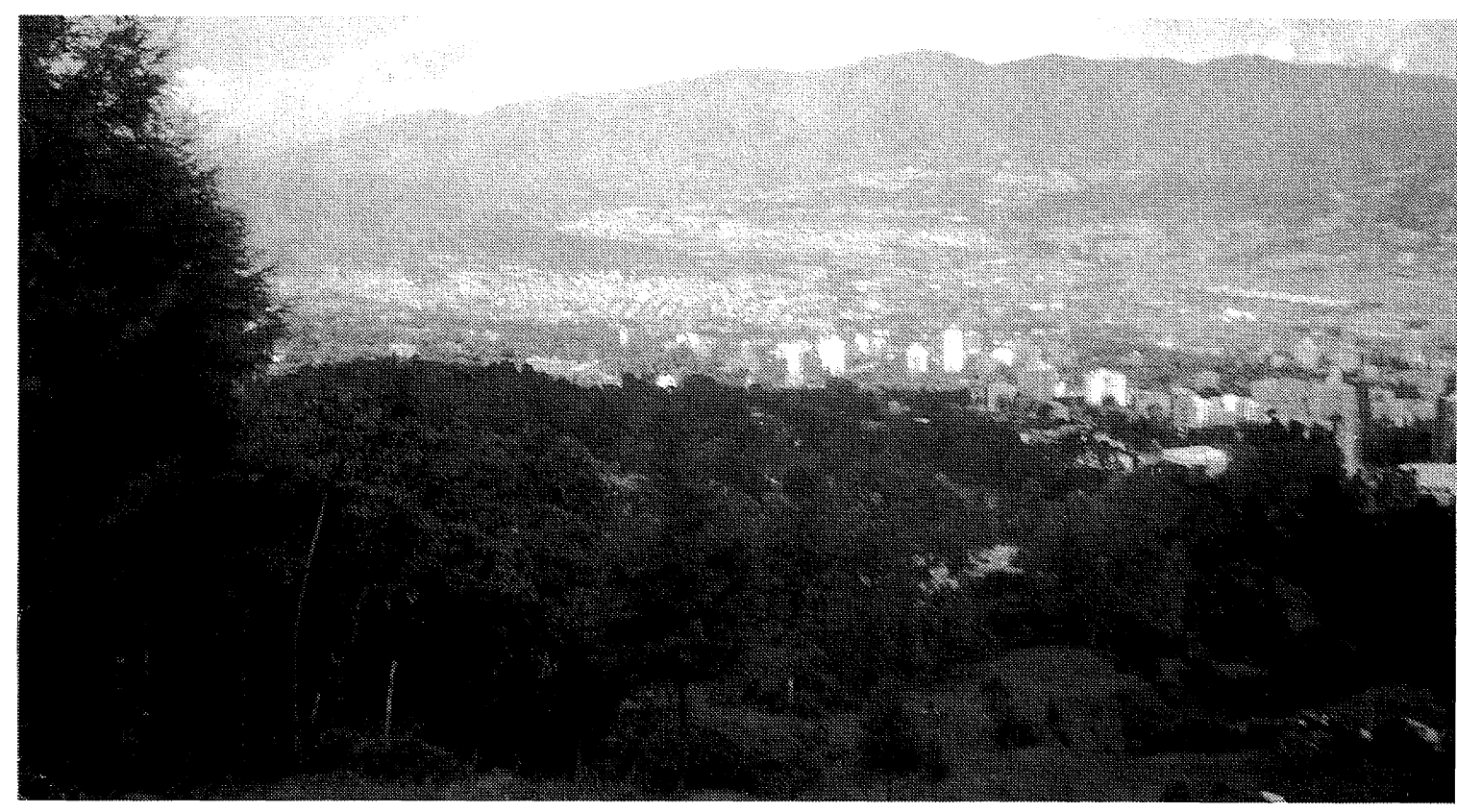

Figure 6. The southern end of the Aburrá Valley from the midway up the eastern hills above EAFIT University. The photograph is taken from an altitude of approximately $2000 \mathrm{~m}$, looking due west along the line of the cross-section shown in Figure 3.

At the upper end of the valley there is some $15 \mathrm{~km}$ between the crests of the hills on either side, with approximately $1-2 \mathrm{~km}$ of reasonably flat alluvial plain to the west of the river and less than $0.5 \mathrm{~km}$ to the east. The hills to the west reach an altitude of 2600 metres. The average slope of the valley side is in the order of $8^{\circ}$, while local inclinations may exceed $20^{\circ}$. Residual soil covering the Altavista bedrock is between 20 and 40 metres deep. To the east, the crest of the hill lies at an altitude of 2820 metres. A sub-horizontal duniteamphibolite contact lies at approximately 1850 metres. Below this interface, both the amphibolite bedrock and residual soil is covered by a significant thickness of debris flow deposits of various ages and weathering. Above the interface, the dunite is covered only by a thin layer of residual soil.

The cross-section extends for 9320 metres either side of the Medellín River, giving a total model width of $18.64 \mathrm{~km}$ (Figure 7). The lower semi-circular boundary of the model extends to a maximum depth of 1500 metres below the free surface in the centre of the valley. This boundary has a radius of 18,000 metres, while the inner boundary of elements where the excitation is input to the model has a radius of 16,800 metres. This geometry is used as the basis for constructing a fine mesh of triangular elements suitable for the finite element computation.

\section{Near-Surface Stratigraphy}

A total of twelve geological units are modelled; three different basement rocks, and nine different nearsurface soft sediments. Of the soft sediments there are three residual soils, five naturally transported deposits, and a small deposit of artificial fill. Each of these units are assigned geotechnical properties (Table 1) on the basis of results from the comprehensive borehole and laboratory testing (GSM, 1999). Both the soil and rock materials are assumed to be isotropic and homogeneous within each layer, while in fact, the real soils are highly anisotropic and inhomogeneous and are not so clearly defined into separate layers as the model assumes. Material properties within each layer may vary considerably both with depth and across their areal extent, and significant care has been taken such that the uniform properties assigned to each unit are representative of the variable reality.

The soft near-surface sediments cover a $13.5 \mathrm{~km}$ width of the model in the centre of the valley between -7325 $\mathrm{m}$ and $+6200 \mathrm{~m}$. The deposits have an average depth of 32 metres, and a maximum depth of 94 metres. The central part of the valley contains a more complex succession of layering resulting from alluvial and debris flow deposition. The two plots in Figure 7 show the geometry of this stratigraphy and topography. The cross-section is defined by a set of linear segments between 2 and 100 metres in length, along stratigraphic boundaries. The degree of geometrical detail used for the bedrock and sediment-layer boundaries is on par with the degree of certainty within existing geological data for Medellín. 


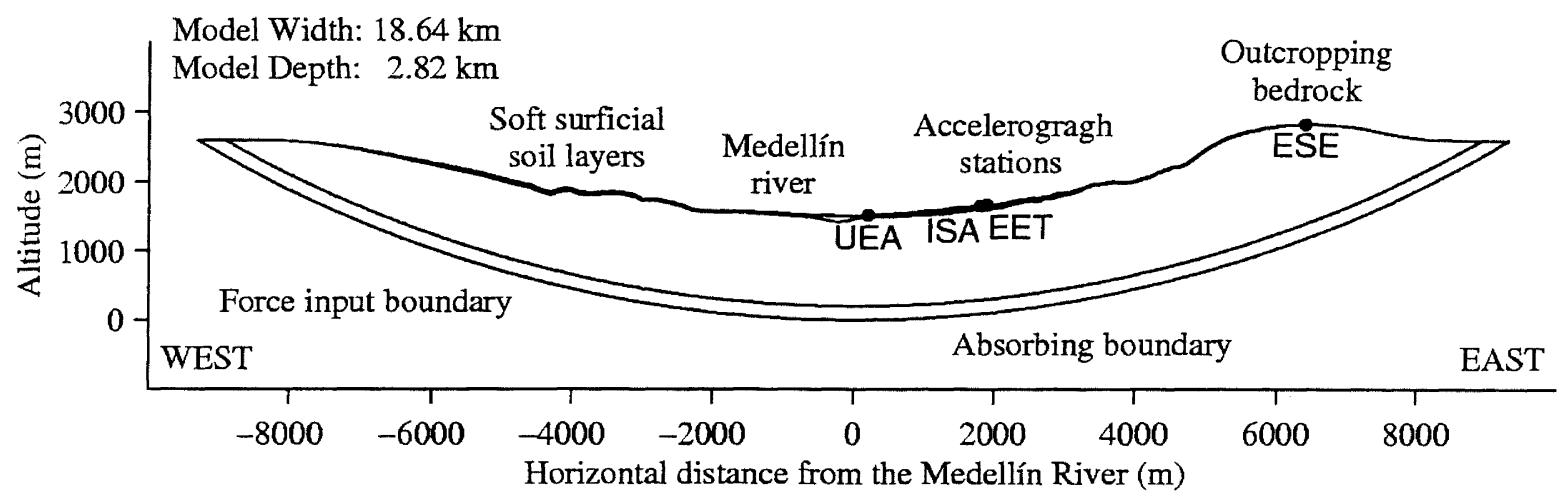

Figure 7. Geometry of the 2-D model through the Aburrá Valley at the location of the cross-section in Figure 3. This geometry was subsequently discretized into a mesh containing 49,900 triangular elements and 102,409 nodes.

Table 1. Elastic material properties of the twelve different geological units modelled in the cross-section.

\begin{tabular}{|c|c|c|c|c|c|c|}
\hline & & ological Unit & Bulk density & Shear velocity & Shear modulus & Damping ratio \\
\hline & SaM & Amphibolite & 2650 & 2000 & 10.600 & 0 \\
\hline$\Xi_{0} \frac{\pi}{8}$ & SuM & Medellín Dunite & 2650 & 2000 & 10,600 & 0 \\
\hline & $\mathrm{SdA}$ & Altavista Stock & 2650 & 2000 & 10,600 & 0 \\
\hline & $\mathrm{KaM}$ & Amphibolite Soil & 1900 & 400 & 304 & 12 \\
\hline$\frac{0}{0}$ & KuM & Medellín Dunite Soil & 1900 & 350 & 233 & 8 \\
\hline & $\mathrm{KdA}$ & Altavista Stock Soil & 1700 & 250 & 106 & 4 \\
\hline & $\mathrm{Qal}_{1}$ & Surface Alluvial Deposits & 1500 & 150 & 34 & 7 \\
\hline & $\mathrm{Qal}_{2}$ & Deep Alluvial Deposits & 1800 & 375 & 253 & 3 \\
\hline 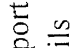 & Qfs & Soil of Debris Flows & 1500 & 200 & 60 & 10 \\
\hline $\bar{\Xi}:$ in & Qfm & Mature Debris Flows & 1600 & 250 & 100 & 7 \\
\hline & Qff & Fresh Debris Flows & 1600 & 250 & 100 & 7 \\
\hline & Q11 & Artificial Fills & 1500 & 150 & 34 & 7 \\
\hline
\end{tabular}

\section{Model Geometry at the Accelerograph Stations}

The line of the cross-section (Figure 3 ) passes only 50 metres north of station UEA, 150 metres north of EET, and 1450 metres north of station ISA. It also passes very close to the position of station ESE on the rock outcrop on the eastern side of the valley. Stratigraphic borehole data from each of the three accelerograph station sites (Table 2) has been integrated into the model in order that results may be compared with recorded weak motions. Sections of the triangular finite element mesh modelling the geology beneath the stations is shown in Figure 9.

Station UEA is located within the grounds of the Universidad EAFIT on the eastern side of the Medellín River. The borehole at this location reaches competent bedrock at a depth of 18.0 metres, above which lies residual amphibolite soil (KaM) and alluvial sediments $\left(\mathrm{Qal}_{1} \& \mathrm{Qal}_{2}\right)$ originating from the Medellín River and 
the nearby Aguacatala creek. The topography around station UEA is very flat with the Medellín River $200 \mathrm{~m}$ to the west and the toe of the gently rising debris flows $200 \mathrm{~m}$ to the east.
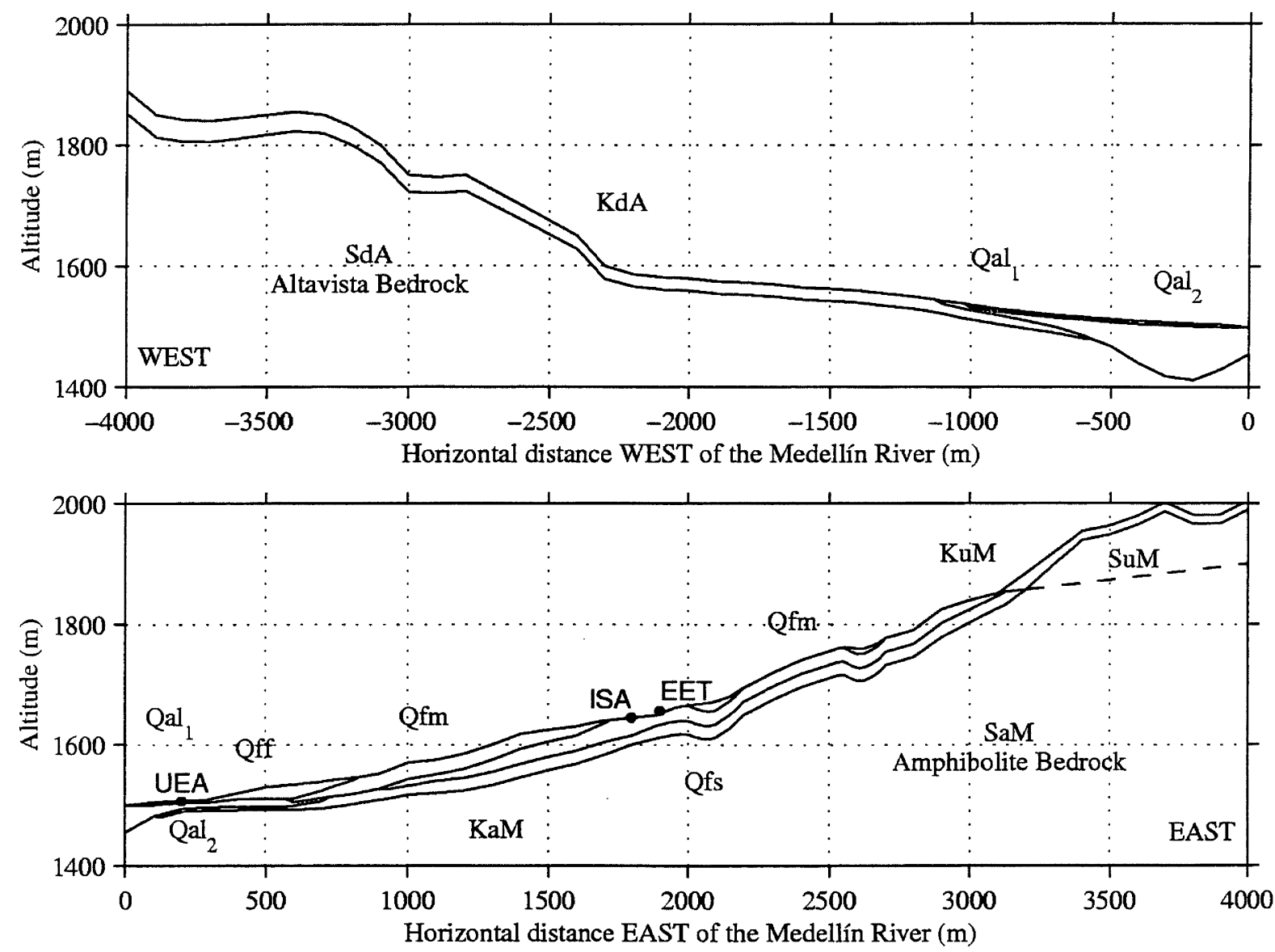

Figure 8. Geometry of the various soft layers modelled across the central $8 \mathrm{~km}$ of the cross-section. The top plot shows the hill slope to the west of the Medellin River, while the bottom plot shows the eastern side. Note the vertical exaggeration.

Table 2. Simplified borehole logs modelling the geology beneath the three stations on the cross-section.
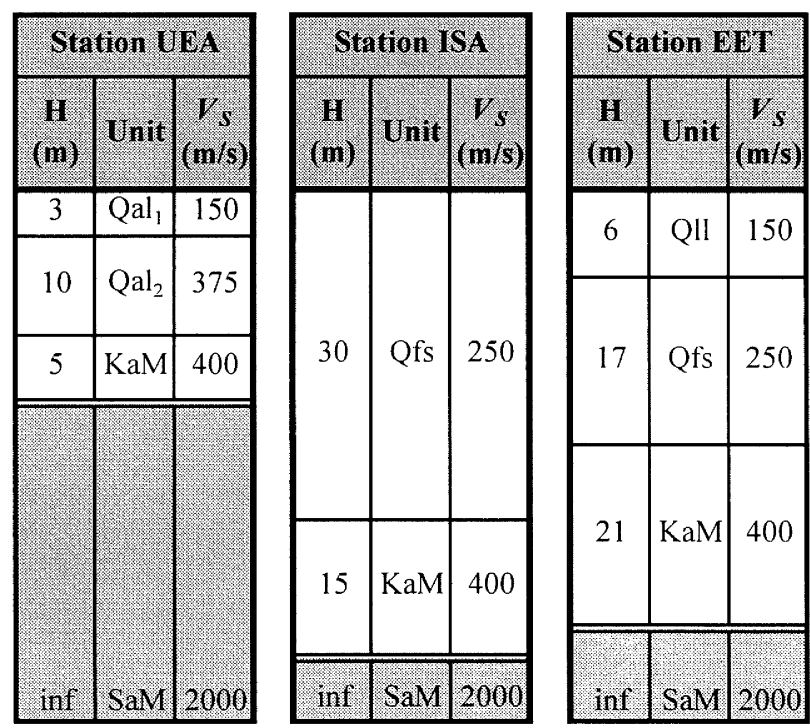
Station ISA is located partway up the slope on the eastern side of the Medellín River. The borehole at this location reaches competent bedrock at a depth of 45.0 metres. The geology here appears to be relatively simple with a single deep layer of very weathered debris flow (Qfs) overlying $15 \mathrm{~m}$ of residual amphibolite soil (KaM). The topography around station ISA is a gently rolling and locally lumpy as shown in Figure 10. Although this station lies over a kilometre south of the cross-section the geology and topography of both hill-slopes is very similar.
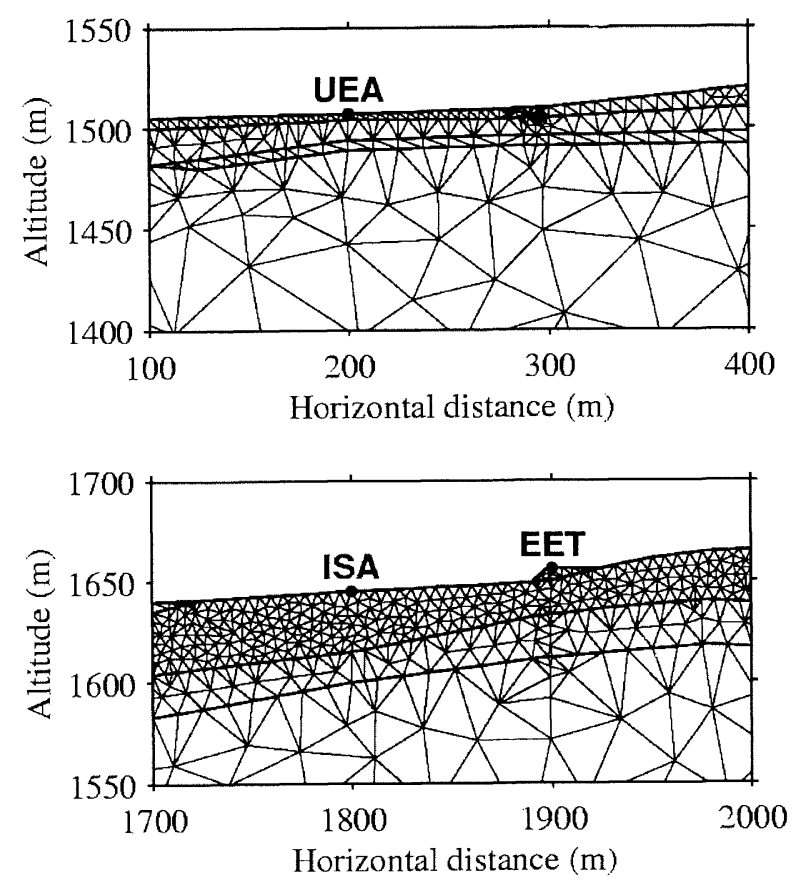

Figure 9. Sections of the finite element mesh modelling the geology beneath accelerograph stations UEA, ISA and EET. Computational efficiency is achieved by tailoring the mesh size with respect to the minimum wavelength found in that layer (a function of the maximum frequency used in the modelling and the shear-wave velocity of the layer). Soil depths and properties are shown in Table 2.

Station EET is located midway up the slope of the eastern hills at a similar elevation to ISA. The borehole at this location reaches competent bedrock at a depth of 44.0 metres below the surface accelerograph which lies on a shallow deposit of artificial fill (Qll) above weathered debris flow material (Qfs) and residual soil of amphibolite (KaM). While the geological model (GSM, 1997) characterises this site adequately to a scale in the order of 50-100 metres, the complex topographic detail at EET is not shown. The accelerograph hut and borehole are located on a small knoll of artificial fill that was most likely deposited during the excavation for the large water tank some 20 metres up-slope. Two metres downhill of the site there is a small sloping bank. Five metres to the north a steep eroding cliff and sloping bank drops down into a $\sim 15$ metre deep gully and a small creek. In an attempt to incorporate this detail into the two-dimensional model station EET has been placed on a small knoll of artificial fill with a steep $6 \mathrm{~m}$ high bank on the downhill side as shown in Figure 9.

\subsection{TWO-DIMENSIONAL FINITE ELEMENT METHOD}

A software package called Archimedes (Bao et al., 1998 ) is used to solve the problem of two-dimensional elastic SH wave propagation within the cross-section. Archimedes is an integrated set of computational software tools for performing large finite element method (FEM) simulations on parallel computers. It was originally developed for two-dimensional elastic simulations (eg. Adams, 2000; Bielak et al., 1999), while three-dimensional (eg. Hisada et al., 1998) and non-linear techniques are now possible. The software was developed at Carnegie Mellon University as part of the Grand Challenge Quake Project (http://www.cs.cmu.edu/ quake/) funded by the US National Science Foundation.

\section{Mesh Generation}

A two-dimensional FEM mesh-generation software package, Triangle (Shewchuk, 1996), uses Delaunay triangulation to create a unstructured mesh tailored in proportion to the local shear-wave velocity, a method which gives similar numerical accuracy and high computational efficiency throughout the geometry of the problem. Seismic motions within the frequency range $0 \leq f \leq f_{\max }$ are simulated with reasonable accuracy when the maximum node spacing is one- 
eighth the shortest wavelength, $\lambda_{\min } / 8=V_{S} / 8 f_{\max }$, where $V_{S}$ is the shear-wave velocity of the unit. The complete mesh contains approximately 49,000 elements with the node-spacing ranging between 3 and 50 metres.

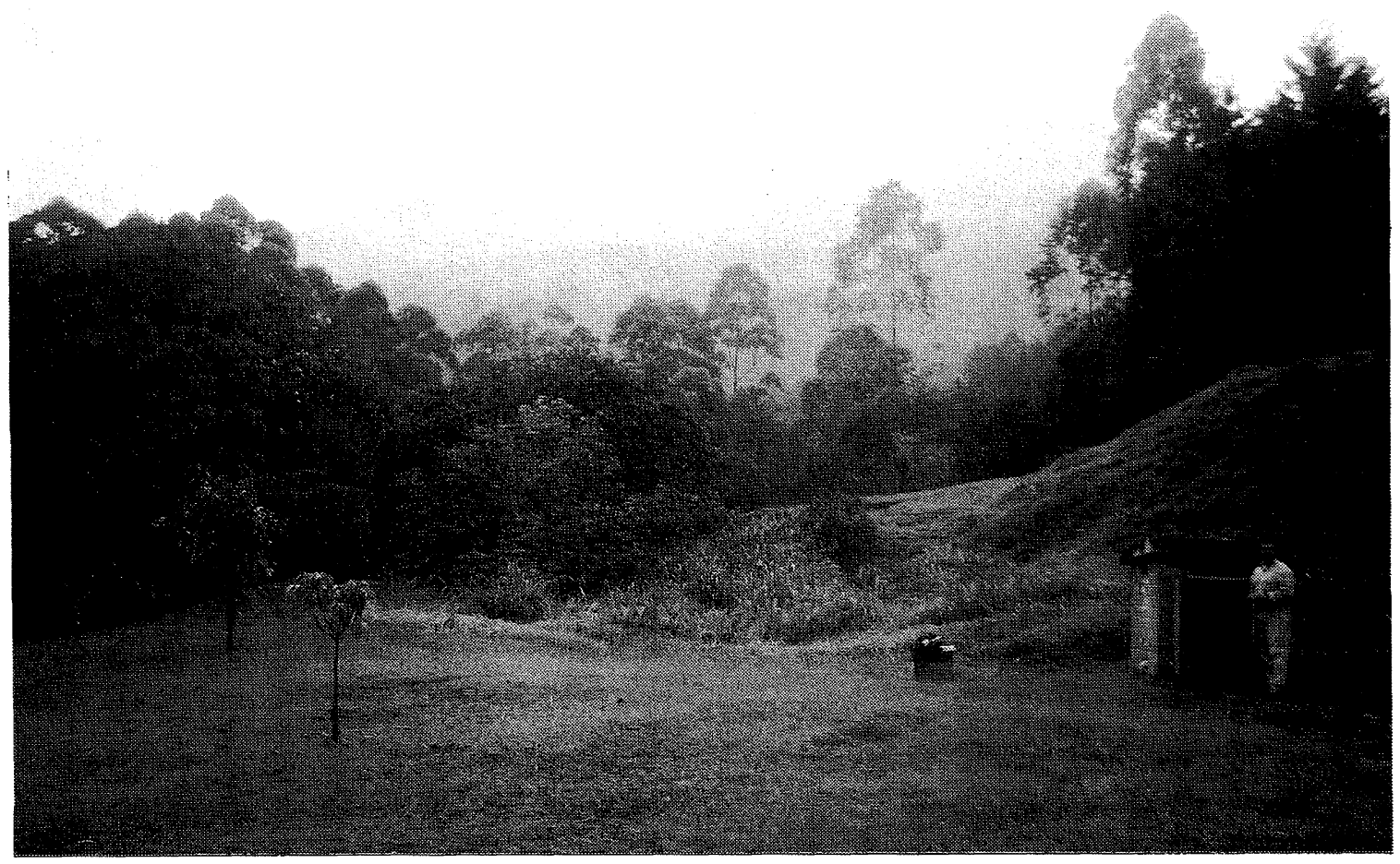

Figure 10. Photograph of accelerograph station ISA with the borehole cover $2 m$ to the left. The topography is gently rolling up to the right.

\section{Finite Element Algorithm}

The problem is one of two-dimensional elastic horizontally-polarised $(\mathrm{SH})$ shear-wave propagation within a heterogeneous soft basin surrounded by a homogeneous half space of rock. The half space is idealised as of uniform cross section and infinite length. With coordinates set with the cross section in the $x-z$ (horizontal-vertical) plane, the anti-plane displacement lies in the long-valley $(y)$ orientation. An FEM analysis allows the whole basin to be treated as piecewise uniform so that the $\mathrm{SH}$ displacement field, $v(x, z, t)$, within each element, satisfies the wave equation.

$$
\rho \frac{\partial^{2} v}{\partial t^{2}}=G\left(\frac{\partial^{2} v}{\partial x^{2}}+\frac{\partial^{2} v}{\partial z^{2}}\right)
$$

Boundary conditions are imposed which require the continuity of force and displacement across each element, and the absence of tractions at the free surface. The equation of motion over the computational domain can then be expressed as a system of ordinary differential equations of the form

$$
[M] \frac{d^{2} v}{d t^{2}}+[C] \frac{d v}{d t}+[K] v=f(t)
$$

where $[\mathrm{M}],[\mathrm{C}]$, and $[\mathrm{K}]$ are the mass, damping and stiffness matrices and $f(t)$ is the applied nodal force.

Archimedes uses a viscous Rayleigh damping model, the parameters of which are set such that the damping ratio averages out to the desired value across the frequency range of interest. A semi-circular absorbing boundary is placed around the lower extent of the model to simulate an infinitely large half-space below the model. Viscous boundary conditions - a distributed set of spring and dashpot models - are imposed on elements of the arc. The circular boundary has the advantage of being easy to describe mathematically as a singular bounding segment.

\section{Input Signal}

The excitation is incorporated into the computational domain along a smaller semi-circular arc inside the absorbing boundary (see Figure 7). The time of excitation of each node on the arc is adjusted so to represent a pulse starting simultaneously over the width of the mesh from the same depth. The method used is that developed by Bielak and Christiano (1984) and 
Cremonini et al. (1988). The input motion is a single vertically propagating Ricker wavelet (Ricker, 1940) with a displacement trace of the form

$$
v(t)=A\left[1-2\left(\omega_{c} t-3 \sqrt{6}\right)^{2}\right] e^{-\left(\omega_{c} t-3 \sqrt{6}\right)^{2}}
$$

where $\omega_{c}$ is the central (dominant or characteristic) angular frequency and $A$ is the wavelet amplitude. The Ricker waveform can be visualised in terms of its displacement trace, $v(t)$, and its Fourier amplitude spectrum as shown in Figure 11 . With a central frequency of $2.0 \mathrm{~Hz}$, the Ricker pulse can be used to study frequencies up to $5.0 \mathrm{~Hz}$.

Ricker wavelet with central frequency, $f_{c},=2 \mathrm{~Hz}$
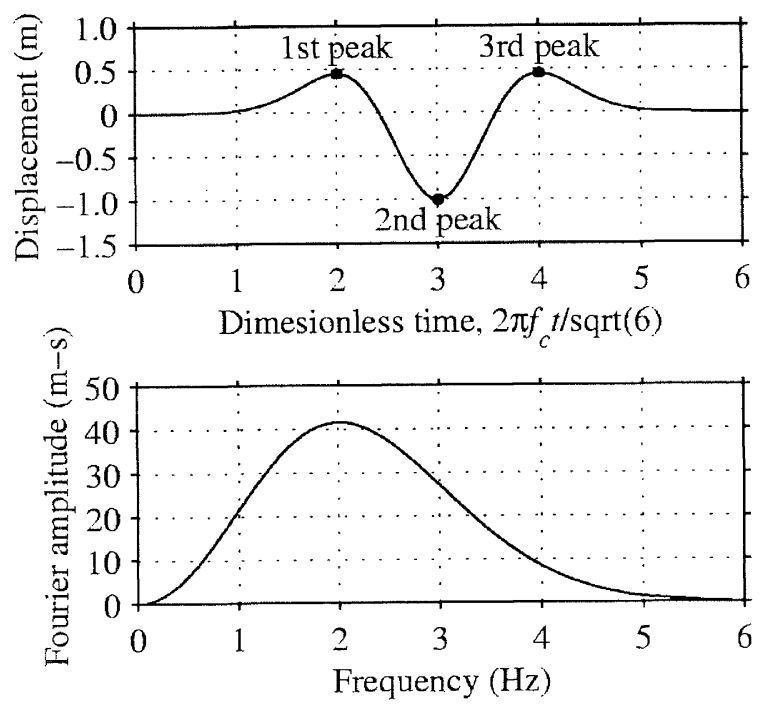

Figure 11. Plots of a $2.0 \mathrm{~Hz}$ Ricker wavelet in time domain and the corresponding Fourier amplitude spectra of displacement showing the central frequency and distribution of amplitude in the frequency domain.

\subsection{ONE-DIMENSIONAL FINITE ELEMENT METHOD}

A short code written in MATLAB is used to calculate the time-domain response of an elastic $\mathrm{SH}$ wave travelling vertically within a column of homogeneous soil and rock units. The computation is similar to that of the two-dimensional Archimedes code. The input excitation is again a Ricker wavelet, while damping and the absorbing boundary are also incorporated in the same fashion to the two-dimensional method.

Using the same geometrical data and material properties that were used in the two-dimensional method, it is possible to calculate the response to a Ricker wavelet at any point across the valley. The onedimensional method requires that the waves be constrained to propagate in only one orientation (the vertical). In this way the possibility of focussing, surface-wave generation and other effects caused by non-horizontal geometry and non-vertical wave incidence is ruled out. The result seen for each given soil column is identical to that given by assuming a uniform stratigraphy extending to infinity in both horizontal directions, and bounded below by a uniform half-space.

\subsection{RESULTS}

Results are presented here from one-dimensional and two-dimensional finite element analyses, and they are compared in both the time and frequency domains. Fourier spectral ratios from the numerical analyses are then plotted against recorded data at three accelerograph stations.

\subsection{TIME-DOMAIN ANALYSIS}

Figures 12 and 13 show displacement seismograms computed across the surface of the Aburrá Valley by two- and one-dimensional analyses, respectively. The output shown is the displacement due to the input of a vertically propagating SH Ricker wavelet with a central frequency, $f_{c}$, of $2.0 \mathrm{~Hz}$.

\section{Amplification of the First Arrival}

The plot in Figure 12 shows an amplified first arrival of the vertically propagating wavefront. The left-handmost contoured ridge is the first (positive) peak of the Ricker displacement pulse arriving at the surface across the full width of the valley. It arrives at the outcropping rock surface at each side of the valley at $t=0$, and is followed closely by the $2^{\text {nd }}$ (negative) and $3^{\text {rd }}$ (positive) peaks. The wavefront is variably amplified and arrives at different times depending on both the altitude and shape of the topography, and the depth, geometry and material properties of any soft layers beneath.

The initial arrivals calculated by the one-dimensional and two-dimensional analyses are compared in Figure 14 for a $5 \mathrm{~km}$ width of the cross-section. While the results of both analyses are in general similar, the 1-D result is much smoother and a function only of the stratigraphic depths and properties, whereas local deviations of the 2-D result from the 1-D result indicate the action of two-dimensional amplification within the model. The mechanisms for the 2-D amplification of these peaks of first arrival are most probably focussing due to the geometry of the soft layers, and focussing due to the geometry of the topography.

\section{Surface Wave Action}

Figure 12 shows little evidence of significant surface wave action generated by the $2-\mathrm{D}$ analysis. This is especially noticeable when compared to similar analyses of narrower basins with deep sediments such as the Lower Hutt (Adams et al., 2000), where strong surface waves are generated at each edge of the valley. 


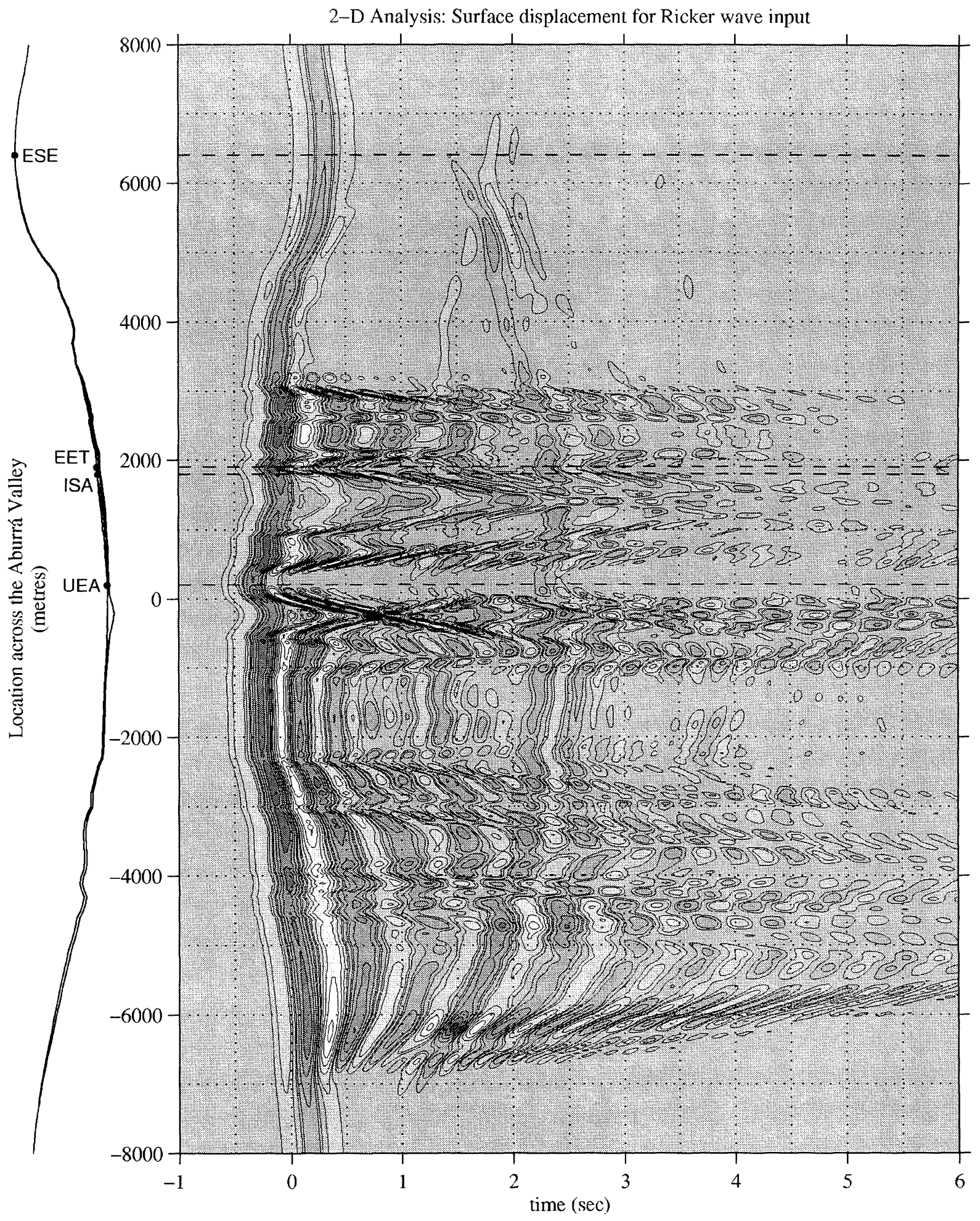

Displacement scale (normalised)

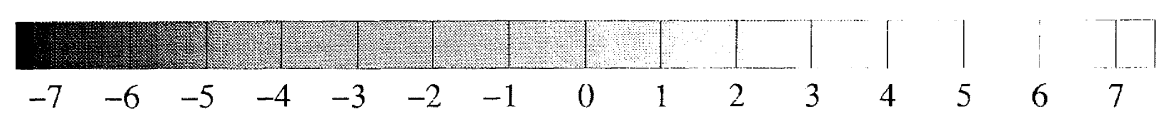

Figure 12. A displacement time-history at the surface from the two-dimensional FEM analysis, plotted as a continuous function of position across the cross-section. Normalised displacement amplitude is shown with shaded contours. Input is a $2.0 \mathrm{~Hz}$ Ricker wavelet as shown in Figure 11. The time scale is adjusted such that the first peak of the Ricker wave reaches the outcropping rock surface at $t=0$. 


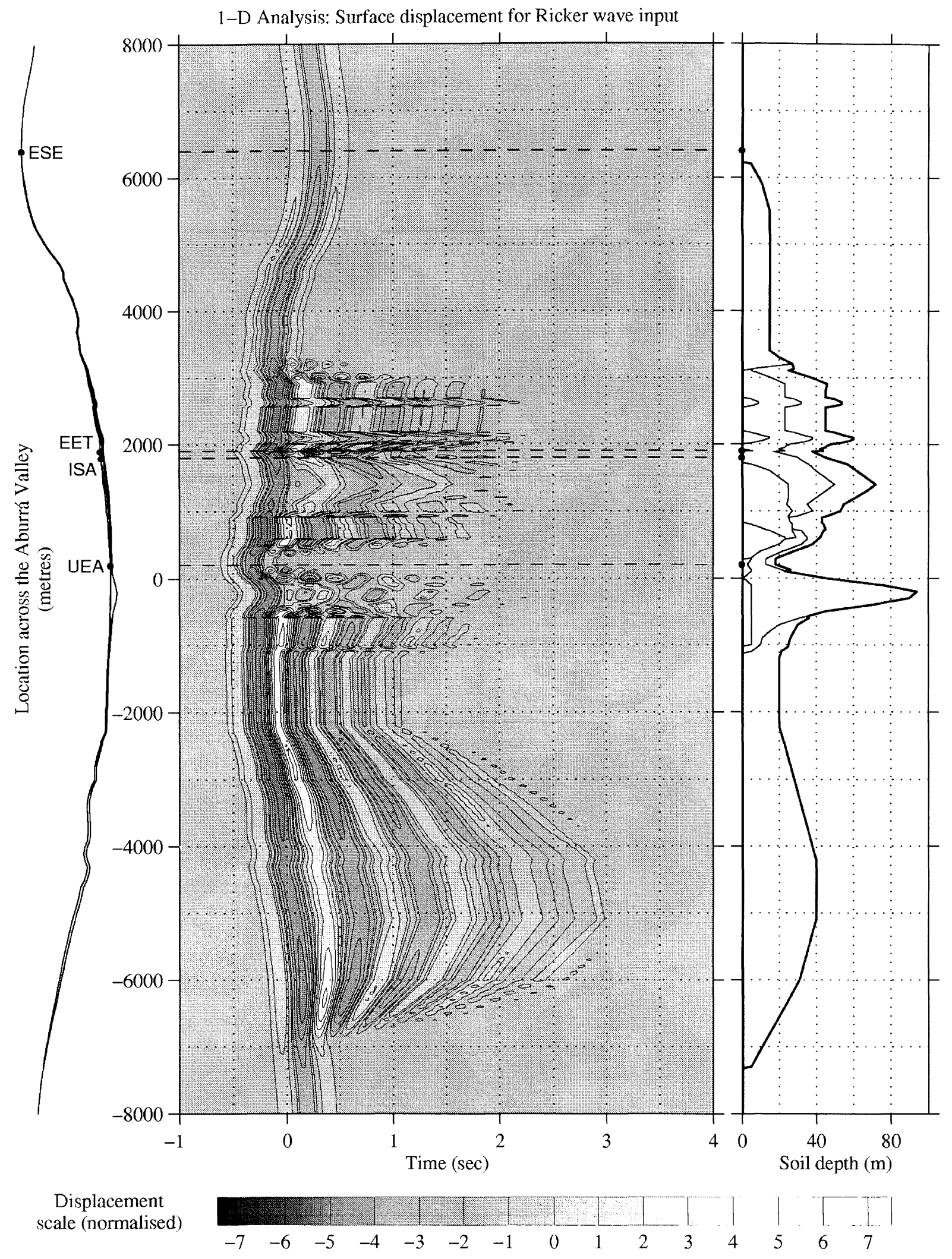

Figure 13. Displacement time-histories at the surface from the one-dimensional FEM analysis of two hundred points across the valley. Input is a $2.0 \mathrm{~Hz}$ Ricker wavelet. Normalised displacement amplitude is shown with shaded contours corresponding to those in Figure 12. The plot of sediment depths shown on the right-hand axis represents the geometrical model used in the 1-D analysis. 
Weak surface waves, however, appear to be generated from small anomalies in the topography at $3800 \mathrm{~m}$ and $5400 \mathrm{~m}$ on the east. Weak surface waves are also generated at the edges of the deep alluvial dip in the centre of the plot, and at the edges of the debris-flow deposits between +1000 and $+1800 \mathrm{~m}$. The former pair of surface waves cause amplification where they interfere constructively at $-250 \mathrm{~m}$. On the whole, this model does not appear to be strongly effected by the presence of surface waves.

\section{Vertical Wave Reflection and Resonance within the Soft Layers}

In some parts of the valley, the $\mathrm{SH}$ wave appears to reflect up and down within the soft surface layers more strongly than at other locations. This can be seen on figures 12 and 13 as a repeated pattern of wavefronts reaching the surface in a fashion that extends or stretches the shape of the initial arrival. In the 1-D analysis these oscillations at the surface decay to insignificant amplitude after only 4-5 cycles of reflection, while in the $2-\mathrm{D}$ results the oscillations continue for up to 12 or more cycles and stretch the shape of the initial arrival in a more complex manner. In general, oscillations continue for the longest in the regions of thickest sediments. This result is highly dependent on the dominant frequency of the input wavelet, which is the reason no oscillations can be seen east of 3000 metres, where the bedrock is overlain by a single thin layer of residual soil of Medellín Dunite. The wavelength of the Ricker pulse is too long compared to the layer thickness for it to be trapped and cause vertical resonance.

\section{Errors due to Incomplete Absorption at the Artificial Boundary}

In the two-dimensional result shown in Figure 12, east of $3000 \mathrm{~m}$, an additional line of branching wavefronts reach the surface 1.5-2 seconds into the simulation. These are an unfortunate scattered reflection from the lower artificial boundary, and subsequent scattering from the free surface. They are the product of an inexact numerical calculation. The spring and dashpot boundaries require a plane free surface and a uniform half-space to completely remove all out-going waves in the model. In the case of the Aburrá Valley, large-scale topography has contributed enormously to the degree of wave scattering and subsequent inefficiency of the artificial boundary.

The additional peaks are a result of focussing of the absorbing boundary reflections due to the shape and position of both the absorbing boundary and the free surface. The reflected wavefronts from the absorbing boundary are highest between $+3000 \mathrm{~m}$ and $7000 \mathrm{~m}$ due to the lack of soil covering, or only a thin covering of stiff soil (KuM). The absence of a deep soft layer causes the bulk of the input energy to be reflected back down into the half-space for removal by the absorbing boundary. The highly scattered nature of the wave renders the absorbing boundary reasonably inefficient in this case. There is also evidence of this numerical inaccuracy across the rest of the basin, especially where it constructs with validly scattered waves within the model. This mechanism appears to be the cause of several erroneously high peaks in the 2 -second range.

\section{Transient Response in the Region of the Accelerograph Stations}

Accelerograph stations UEA, ISA and EET lie on the lower eastern side of the valley above complex subsurface stratigraphy as shown in Figure 14. The computed transient response at the stations UEA, ISA and EET is shown in Figure 15. On the western edge of the large alluvial dip, between $-700 \mathrm{~m}$ and $-600 \mathrm{~m}$, the amplification of the first arrival is significantly higher in the 2-D analysis. This appears to be some form of edge effect either in the residual soil ( $\mathrm{KdA})$ extending west from this point, or in the alluvial dip to the east. Within the alluvial dip ( $-600 \mathrm{~m}$ to $+100 \mathrm{~m}$ ) surface waves are clearly visible, being generated at the edges by the first arrival and travelling back and forth across the small basin for several cycles. The amplitude of these waves is much reduced after the first crossing of the alluvium due to its poorly defined edge (as it grades into adjacent thinner layers) with correspondingly poor horizontal reflection characteristics.

At the site of station UEA, only 100 metres east of the alluvial dip, there is little evidence of the weak basin effect although amplification of the first arrival is slightly higher from the 2-D analysis. Although this position in the model is characterised reasonably well by the 1-D analysis, there is still evidence of minor multi-dimensional effects. In the debris-flow deposits to the east of station UEA the 2-D analysis produces many local deviations from the 1-D amplification of the first arrival yet the general trend in Figure 14 is very one-dimensional. On Figure 12, however, weak surface waves appear to travel across the sediments with the effect of lengthening the increasing the number of oscillations in the 2-D result.

At station ISA, the peaks in Figure 15(b) are amplified more in the 2-D result and the oscillations continue for longer. At station EET, the 2-D peaks are amplified significantly more than the 1-D. The shape of the displacement traces at EET in Figure 15(c) are also very different, and the shaking more prolonged in the 2-D. It appears that two-dimensional effects at EET are a result of both the protruding knoll of artificial fill and the deeper soft layers also found at ISA. 


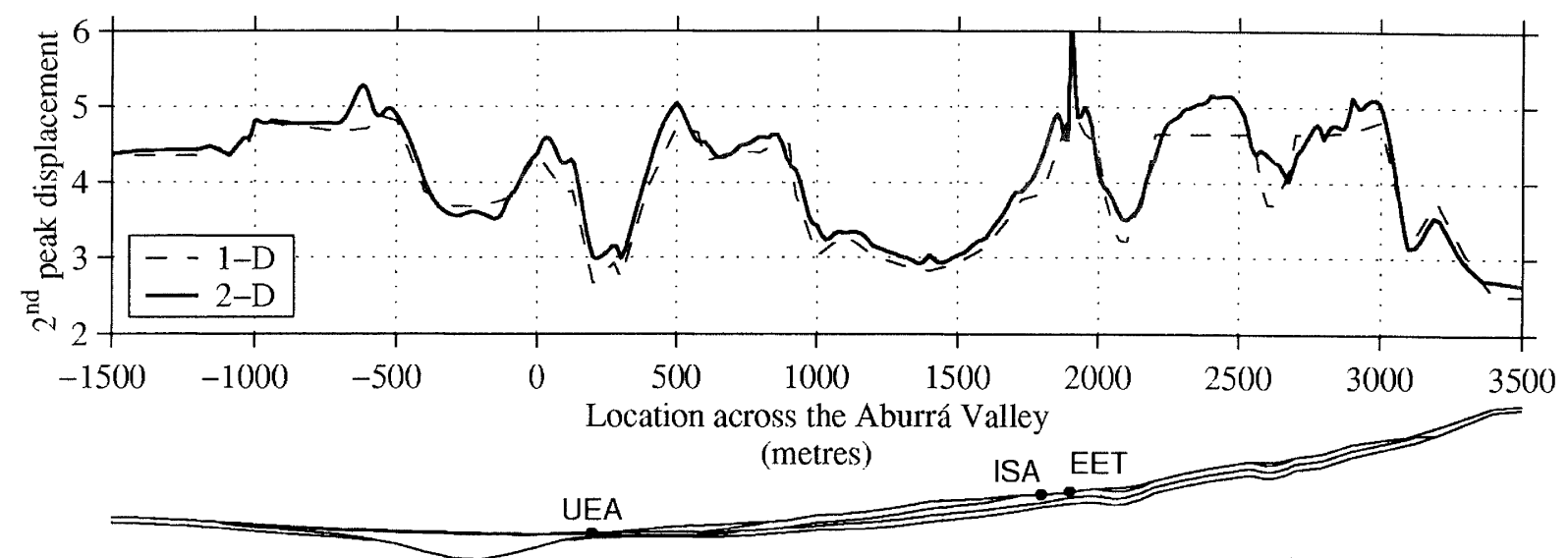

Figure 14. Plots showing the displacement amplitude of the $2^{\text {nd }}$ (central) peak of the Ricker wavelet (figure 11) when it first arrives at the surface. Results from both one-dimensional and two-dimensional analyses are shown over a $5 \mathrm{~km}$ width of the valley to the centre-east. Displacement is normalised against the 2.0 $\mathrm{Hz}$ input wavelet such that amplitudes are positive.
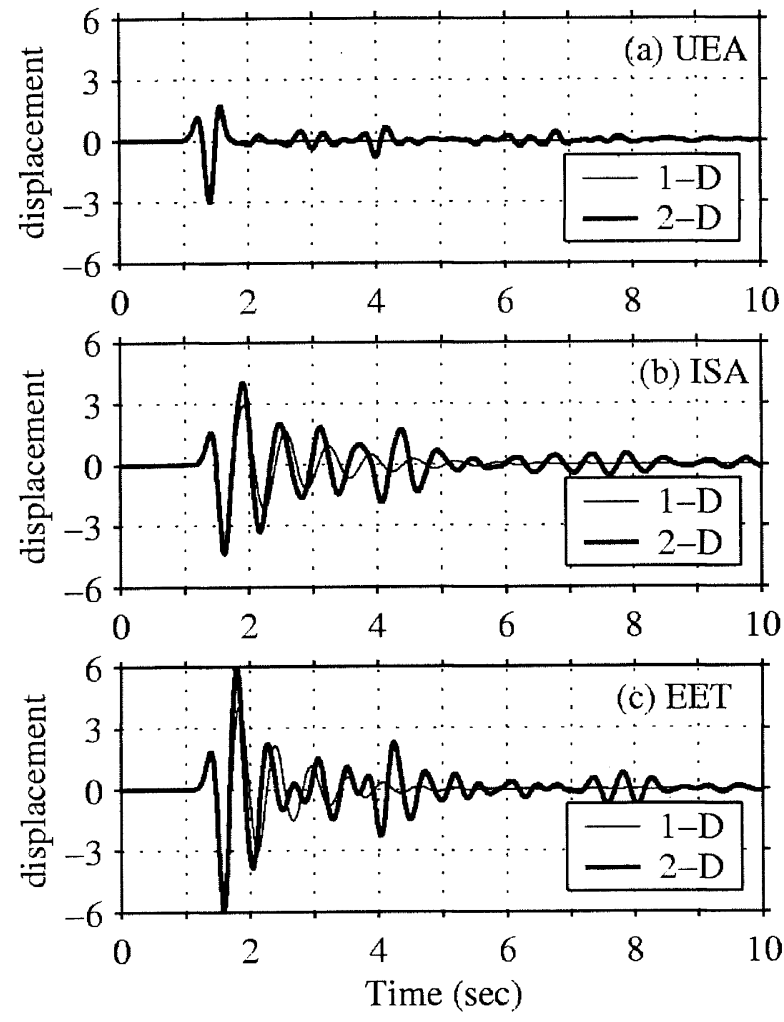

Figure 15. Displacement time-histories at accelerograph stations UEA, ISA and EET for a $2.0 \mathrm{~Hz}$ Ricker wave input. Onedimensional and two-dimensional results are compared.

\subsection{SPECTRAL ANALYSIS}

Figures 16 and 17 show plots of Fourier spectral ratio (FSR) computed across the surface of the Aburrá
Valley by two- and one-dimensional analyses, respectively. The FSR is the ratio of Fourier amplitude from a recording on the soil surface to a simultaneous recording on a bedrock outcrop. When calculating FSR from numerical results, the input ground motion (multiplied by two, to account for the free-surface doubling effect) is substituted for the outcrop motion. Consequently the FSR has an approximate value of unity for all frequencies on the rock outcrops to either side of the valley, while within the valley the FSR shows a complex pattern of amplification.

\section{A Comparison between One- and Two-Dimensional Analyses}

The 1-D result in Figure 17 appears to correctly predict the approximate position of the main peaks in the 2-D result (Figure 18), yet it does not reproduce any of the very high FSR values nor the spatial variability thereof. FSR in the 1-D results reach a maximum of 8.7 between $-5000 \mathrm{~m}$ and $-4000 \mathrm{~m}$, and the spectral amplification is generally quite uniform across the whole valley with an average peak FSR of around 7 . The frequency at which this peak occurs is a simple function of the depth and properties of the layers below.

In the 2-D results the FSR peaks at more than 18 at several locations. In most cases, the frequency at which maximum amplification occurs is very similar to the 1$\mathrm{D}$ prediction. The strong spatial variability and amplification shown in Figure 16 is clear evidence of two dimensional effects, such as focussing, surface wave action and horizontal resonance. These appear to occur over the whole of the soft part of the valley. 


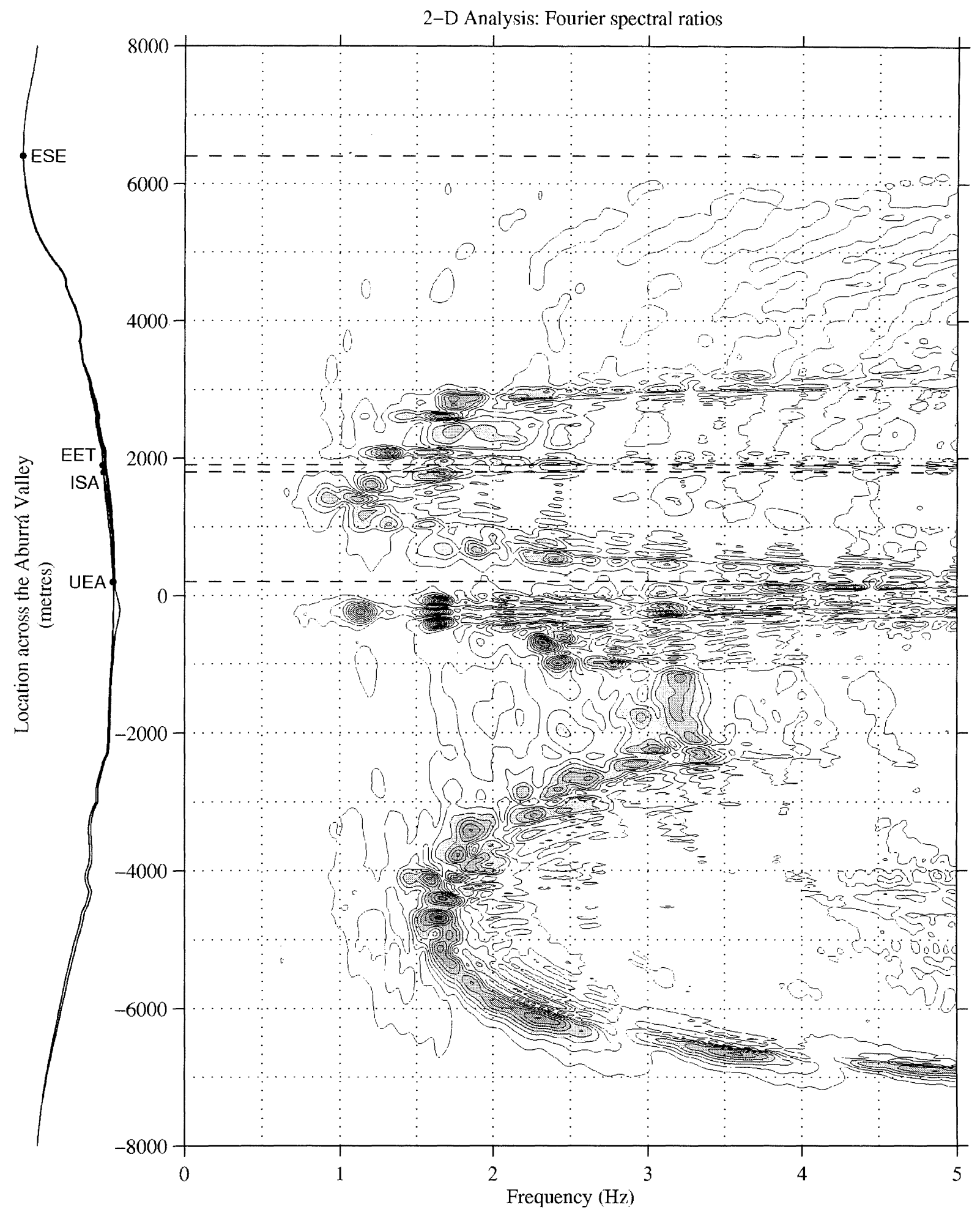

Fourier spectral ratio (FSR)

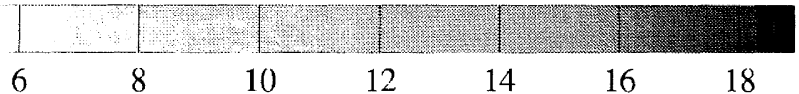

Figure 16. Fourier spectral ratios at the surface from the two-dimensional FEM analysis, plotted as a continuous function of position across the cross-section. FSR is shown with shaded contours. 


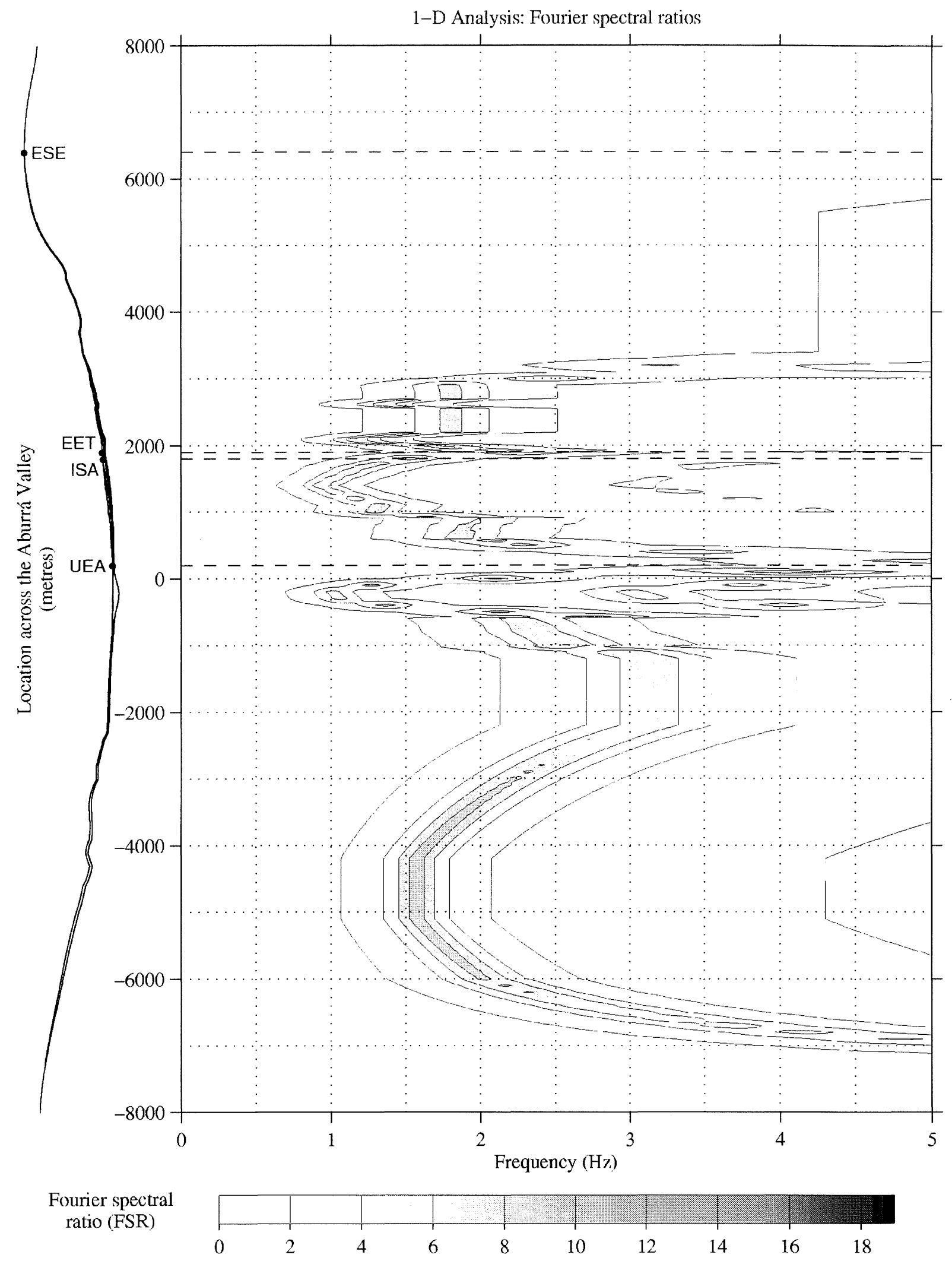

Figure 17. Fourier spectral ratios at the surface from the one-dimensional FEM analysis of two hundred points across the valley. FSR is shown as a colour scale that corresponds to the scale of Figure 16. 

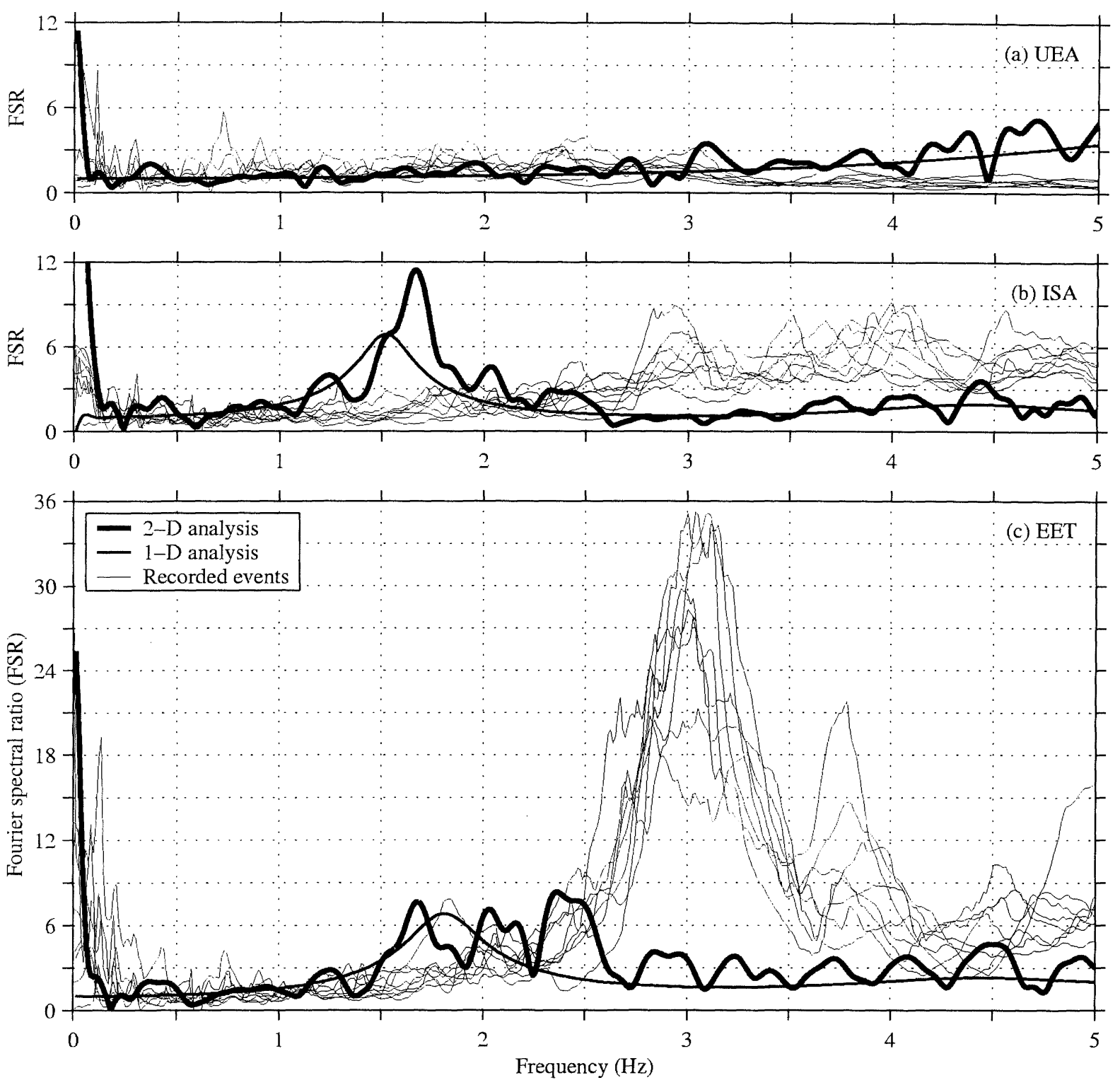

Figure 18. A comparison of Fourier spectral ratios at stations UEA, ISA and EET obtained by two-dimensional (thick line) and one-dimensional (medium line) finite-element modelling, with Fourier spectral ratios calculated from the nine events in Table 3 (thin lines). Note the wide range in FSR between stations.

In addition to the large peaks in the results on Figure 16 , there exists a background valley-wide spectral pattern. This is shown as curved low amplitude contours most noticeably on the eastern (top) portion of the plot. These lines are not observed in the results of the one-dimensional analysis in Figure 17, nor are they observed outside the zone of soft soil in the twodimensional results. The origin of this pattern is possibly a weak whole-valley soft-soil response, or a whole-valley topographic response. It may also be influenced by unwanted numerical reflections from the artificial boundary.

Frequency Response in the Region of the Accelerograph Stations
Within the alluvial dip between to the west of UEA the spectral peaks show a clear pattern of two-dimensional resonance (Bard and Bouchon, 1985) such as was found in the Lower Hutt Valley (Adams et al, 2000). Two-dimensional resonance is set up when standing waves in both the horizontal (between the sides of the deposit) and vertical (between the basement and the free surface) orientations are superimposed upon each other. The resulting spectral plots show a distinctive pattern of extremum and nodal points across the ground surface (Bielak et al., 1999). The very strong single peak at $1.15 \mathrm{~Hz}$ and triple peak at $1.65 \mathrm{~Hz}$ represent the $1^{\text {st }}$ and $3^{\text {rd }}$ horizontal resonant modes (respectively) of the $1^{\text {st }}$ vertical resonant mode. The lower amplitude $5^{\text {th }}$ and the $7^{\text {th }}$ horizontal modes can also be seen at $2.10 \mathrm{~Hz}$ and $2.40 \mathrm{~Hz}$ respectively. At 
$3.15 \mathrm{~Hz}$ a further centrally located $(x=250 \mathrm{~m})$ peak indicates the onset of the $2^{\text {nd }}$ vertical mode.

Two-dimensional resonance effects also occur in the thick layer of debris-flow and residual deposits between $+300 \mathrm{~m}$ and $+3100 \mathrm{~m}$. Within this zone there appears to be a complex interaction of several resonance patterns of different size-scales. The largest of these is the full 2800-metre-width, which forms a (rather hypothetical) weak two-dimensional resonance pattern. Within this, the 1600-metre-width between $+300 \mathrm{~m}$ and $+1900 \mathrm{~m}$ forms a well-defined twodimensional pattern. On an even smaller scale, the small deposits of Qfm at $+2100 \mathrm{~m}$ and $+2600 \mathrm{~m}$ generate small basin-resonances of their own. The horizontal resonance component within any of these patterns does not appear to be strong enough to generate a fully formed two-dimensional pattern; rather only the two-dimensional modes that coincide with the one-dimensional pattern are visibly amplified. At any point within the debris-flow deposits, it is difficult to determine how much of the response is due to resonance set up within the whole deposit or half of the deposit, or whether it is just a very local effect.

The site that models accelerograph station UEA lies in a position whereby it escapes most of the resonant effects generated within both the large alluvial dip to the west, and the debris-flow deposits to the east. Some of these adjacent effects do however leak across to this site creating the highly irregular (yet low) 2-D FSR shown in Figure 18(a). This site is so shallow that its fundamental vertical resonant frequency lies at around $6 \mathrm{~Hz}$, outside the author's domain of interest $(0-5 \mathrm{~Hz})$.

Station ISA lies on the edge of the weak twodimensional resonant pattern generated within the deposits between $+300 \mathrm{~m}$ and $+1900 \mathrm{~m}$ (described above). It has the misfortune to be located at the position of a strong, highly amplified anti-node in the pattern at a frequency of $1.7 \mathrm{~Hz}$.

The site of station EET (+1900 m) appears to lie within the influence of two-dimensional effects from the basin-like structure of debris flow deposits to the west, and also the thinner deposits immediately to the east. In addition to this, site EET is undoubtedly influenced by the small knoll of artificial fill shown in Figure 9. The 2-D result plotted in Figure 18(c) shows three main peaks in the Fourier spectrum between 1.7 and $2.6 \mathrm{~Hz}$ and a maximum FSR of 8 .

\subsection{COMPARISON WITH RECORDED DATA}

Fourier spectral ratios modelled at each of the three accelerograph stations on the cross-section (UEA, ISA and EET) are compared with Fourier spectral ratios calculated from weak motions recorded at these sites and station ESE; which is sited on outcropping bedrock to the south-east of Medellín.

\section{Recorded Weak Motions}

The response of each of the three stations of interest is investigated during nine different events that triggered the reference station ESE during the period between May 1997 and October 1998. These events are summarised in Table 3. Five of these events originate from the deep Bucaramanga Nest, two from shallow events in the area south-west of Bucaramanga, while the final two originate from the southern Veijo Caldas Seismic Zone. The north-south (NS) component is examined as this corresponds with the out-of-plane motion modelled in the two-dimensional cross section.

Table 3. Seismological characteristics and peak recorded accelerations (north-south component only) at stations ESE, UEA, ISA and EET for nine distant earthquakes.

\begin{tabular}{|c|c|c|c|c|c|c|c|c|c|c|c|}
\hline \multirow{2}{*}{ Date } & \multirow{2}{*}{$\begin{array}{l}\text { Time } \\
\text { (UTC) }\end{array}$} & \multirow{2}{*}{$\begin{array}{l}\text { Lat } \\
\text { (N) }\end{array}$} & \multirow{2}{*}{$\begin{array}{l}\text { Long } \\
(W)\end{array}$} & \multirow{2}{*}{$\begin{array}{l}\text { Depth } \\
(\mathrm{km})\end{array}$} & \multirow{2}{*}{$\mathrm{M}_{\mathrm{L}}$} & \multirow[t]{2}{*}{ Seismic Source } & \multirow{2}{*}{$\begin{array}{l}\text { Distance } \\
\text { (km) }\end{array}$} & \multicolumn{4}{|c|}{$\begin{array}{l}\text { Peak NS Acceleration } \\
(\mathrm{cm} / \mathrm{s} 2)\end{array}$} \\
\hline & & & & & & & & ESE & UEA & ISA & EET \\
\hline 11-May-97 & $18: 17$ & 6.74 & 73.18 & 150 & 5.8 & Villanueva ${ }^{\mathrm{BM}}$ & 309 & 1.1 & 0.8 & 3.0 & 8.6 \\
\hline 11 -Jun-97 & 07:07 & 6.81 & 72.96 & 160 & 6.0 & Cepita $^{\mathrm{BM}}$ & 336 & 0.9 & 0.7 & 2.5 & 7.6 \\
\hline 11-Jun-97 & $19: 10$ & 6.84 & 73.09 & 150 & 6.1 & Los Santos ${ }^{\mathrm{BM}}$ & 320 & 1.4 & 1.1 & 3.2 & 10.1 \\
\hline 24-Jun-97 & $17: 54$ & 6.87 & 73.23 & 150 & 5.5 & Zapatoca $^{\mathrm{BM}}$ & 307 & 0.9 & & 1.4 & \\
\hline 2-Sep-97 & $12: 14$ & 3.93 & 75.68 & 150 & 6.3 & Roncesvalles $^{\mathrm{VC}}$ & 295 & 3.1 & 3.6 & 10.0 & 25.0 \\
\hline 11-Dec-97 & $07: 56$ & 4.00 & 75.95 & 220 & 6.6 & Génova ${ }^{\mathrm{VC}}$ & 333 & 3.8 & & 6.6 & 13.0 \\
\hline 6-Mar-98 & $09: 37$ & 6.28 & 73.89 & 30 & 5.4 & Cimitarra $^{\mathrm{SH}}$ & 186 & 8.8 & 2.5 & 9.5 & 30.0 \\
\hline 8-Mar-98 & 04:59 & 6.30 & 73.88 & 30 & 5.4 & Cimitarra $^{\mathrm{SH}}$ & 187 & 7.2 & 3.7 & 15.0 & 49.7 \\
\hline $10-$ Oct- 98 & $21: 55$ & 6.85 & 72.90 & 160 & 5.7 & San Andrés ${ }^{\mathrm{BM}}$ & 343 & 0.5 & 0.3 & & 2.9 \\
\hline
\end{tabular}


Of the accelerograph stations shown in Table 3, the lowest accelerations are generally found at station ESE on the rock. Accelerograph UEA located on only a shallow depth of alluvium, however, also records comparable low peak values. Accelerograph ISA records peak accelerations between 2 and 3 times larger than those at ESE, while accelerograph EET records peak accelerations 3-10 times that of ESE.

Using accelerograph station ESE as the reference rock site, Fourier spectral ratios have been calculated at the other three stations for the nine earthquakes in Table 3 . These are plotted in Figure 18 along with the numerically computed $1-D$ and $2-D$ results. The Fourier spectral ratios from recorded data show significant variation in amplitude between events, yet in general display similar peaks in frequency. Peak FSR reaches 5.9 for station UEA, 9.1 for station ISA, and a very large 35.2 for station EET at an apparently highly resonant frequency of $3.0 \mathrm{~Hz}$.

\section{Accelerograph Station UEA}

Figure 18 shows some correlation between the 2-D result and recorded events over the frequency range 0-3 $\mathrm{Hz}$. Although the many small peaks in this region do not agree, the range of FSR between 1 and 2 is comparable. The small peaks in this band are likely to be a result of resonance effects in adjacent deeper layers, rather than a fundamental frequency associated with the shallow depth of soil at this site. Above $3 \mathrm{~Hz}$, the recorded FSR at station UEA drops below unity, indicating that the higher frequencies are amplified less at UEA than at ESE. Both the 2-D and 1-D models predict a fundamental frequency of around $6 \mathrm{~Hz}$ at UEA, yet this is not shown in any of the recorded data.

\section{Accelerograph Station ISA}

Both the 2-D and 1-D models predict a strong fundamental frequency of $1.5-1.7 \mathrm{~Hz}$ at this site. Amplification from the 2-D analysis is significantly higher due to its misfortune of being located on an antinode within a two-dimensional amplification pattern. Fourier spectral ratios calculated from recorded data at ISA, however, do not show this fundamental mode at all. Rather they show amplification of frequencies in the 2.5-5.0 Hz band, up to a FSR of 3-9. On the whole, there appears to be little correlation between the modelling results and recorded data at this site.

\section{Accelerograph Station EET}

At accelerograph station EET there appears to be a large discrepancy between recorded and modelled frequency spectra. Two-dimensional modelling predicts a wider and stronger band of amplification than the one-dimensional result for frequencies between 1.7 and $2.7 \mathrm{~Hz}$, yet neither is able to predict the very strong resonant frequency of $3.0 \mathrm{~Hz}$ that is evident in the recorded motions. An average FSR of 27.3 for recorded motions at this frequency is obviously a result of something other than the one- and two-dimensional effects modelled in this study.

\subsection{DISCUSSION}

The Aburrá Valley at Medellín appears to have a very complex seismic site response; a product, essentially, of its highly irregular near-surface geology. The variable yet thin covering of soil within such a large valley means that the response of the valley as a whole is less important than the response due to smaller-scale topographic and sub-surface features.

The geology of the Aburrá Valley is very unlike most of New Zealand. There are many different types of soft near-surface material, including residual soils, debrisflow deposits, alluvial deposits and artificial fills. The stratigraphy of these units is far from horizontal, with significant depths of soft material extending well up the sides of the valley. The boundaries between the geological units is sometimes very sharp (eg. between alluvial deposits and bedrock), but often more of a gradation (eg. between residual soil and bedrock).

The basement rocks are also of many different types, with several intrusive igneous bodies within older metamorphic units. While the spatial distribution and nature of surface geology has been carefully mapped; the depth, geometry and characteristics of the bedrocksoil interface are not understood in great detail. An indication of the possibly highly-irregular geometry of this interface is given by the Cerros Nutibara, Volador and Picacho and other hills of outcropping basement rocks, as well as a postulated tectonic structure through the centre of the valley. Thus, without a good understanding of the geometry of the basement, and a widely-spaced set of borehole logs providing information at only discrete points, a sometimesdubious interpolation has been employed to create the two-dimensional model.

The abruptness of this interface between the competent basement rock and the overlying softer layers is undoubtedly a major contributor to the seismic response of the site. Residual soils invariably form a gradation from soft soil down to intact rock. And in fact the soil-rock interface is more of a transition than an interface. Davis (1995) shows how the weathered transition zone between residual soil and basement rock may have the effect of flattening the amplitude spectrum, especially at high frequencies. The is however, evidence in roadway cuttings (eg. Figure 4) that the transition from residual soil $\left(\mathrm{V}_{\mathrm{S}} \sim 400 \mathrm{~m} / \mathrm{s}\right)$ to competent rock $\left(\mathrm{V}_{\mathrm{S}} \sim 2000 \mathrm{~m} / \mathrm{s}\right)$ may in general be fairly abrupt, perhaps in the order of one to two metres wide. The interface between various layers of debrisflow, alluvial and other deposits, is in most cases quite 
sharp as indicated from seismic velocity profiles, but not necessarily very regular or smooth.

Seismic velocity data from borehole tests indicate that the shear-wave velocity often increases gradually with depth within layers of similar composition. Davis and Hunt (1994) indicate that by taking an average shearwave velocity and modelling each layer as homogeneous (as is done in this study), it is likely that the amplification especially at higher frequencies is somewhat under-estimated

In a complex geological situation of this type, the amplitude of the response at any point within the valley is dependent on the nature and geometry of the surrounding topography and sub-surface geology. This is called a multi-dimensional effect, as opposed to onedimensional effects, whereby the amplification depends only on the depth and properties of soil below the site. Multi-dimensional effects may occur on both small and large geographic scales. For example, the amplification of a small deposit of artificial fill in an otherwise extensively flat terrain is most likely to be a function of the local nature of that fill, rather than the uniform surroundings; whereas the amplification at a site on a thick uniform deposit within a large steepsided valley is more likely to be function of the geometry and nature of that valley, than of the locally uniform nature of the site.

In modelling the Aburrá valley with both one- and twodimensional methods, it has been shown that the seismic response at most locations is clearly due to a combination of one- two- and even three-dimensional effects. Multi-dimensional effects appear to exist on both small and large scales. Within the twodimensional results, spatially variable and peaked amplifications of the first arrival of the Ricker wavelet is indicative of topographic and/or sub-surface stratigraphic focussing at many locations across the valley. Due to the relatively shallow depths of soil, this phenomenon is generally very local in nature. Other small-scale multi-dimensional effects observed in the Aburrá Valley model include strong horizontal resonance in small and well-defined soft deposits, and strong shaking of sharp topographic features such as the artificial deposit at station EET.

On a slightly larger scale, multi-dimensional resonance within sub-basin structures and thick soil deposits appears to influence the response across much of the valley. In the two-dimensional modelling there is clear evidence of strong two-dimensional amplification both within the alluvial dip in the centre of the valley, and debris-flow deposits on the eastern slope. Neither of these structures is particularly well constrained in the horizontal direction, and for that reason the higher mode horizontal resonances are not well developed. The net effect is a spatially-peaked and highly amplified pattern of resonance occurring at frequencies similar to those from the one-dimensional analysis.

For any given site within the Aburrá Valley, it is therefore essential to consider a significant volume of surrounding geology in order to predict the seismic response at that site. The author's results, however, show little influence from the overall large-scale dimensions of the valley. Rather, the structures within the valley on smaller scales from a few kilometres to a few metres wide appear to have the greatest influence on the results. These structures include well-defined dips and basins in the basement rock, localised thick depths of soft material that may act as resonators in the horizontal plane, and topographic features such as small side-valleys, gullies, banks, cliffs, sharp ridges and knolls. The incorporation of these features into a site-response model of the Aburrá Valley is crucial, while the incorporation of the whole valley is perhaps not quite so necessary.

The highly variable nature of the topography and nearsurface geology exists in not only two, but all three spatial dimensions. Two-dimensional modelling has shown the nature and extent of the response due to the east-west horizontal dimensions of the valley and nearsurface materials. As for the long-valley (north-south) dimension, the two-dimensional results have given an indication of its likely influence on the response. It appears that there will be little influence from the longvalley dimensions on a scale larger than $4-5 \mathrm{~km}$, yet on a smaller scale of order less than $1-2 \mathrm{~km}$, there may be significant effect from side valleys, ridges and horizontally discontinuous deposits. Thus, although two-dimensional modelling has produced substantial insights into the problem, it is not an adequate way to completely characterise site response within the Aburrá Valley. A three-dimensional study is undoubtedly essential for a more realistic solution.

The Aburrá Valley is very large both in height and width. The $18.6 \mathrm{~km}$-wide and $2.8 \mathrm{~km}$-deep finite element mesh contained 49;000 triangular elements and 102,409 nodes. A model of these dimensions is bordering on what is possible to analyse with Archimedes on a single $512 \mathrm{MB}$ processor (of course Archimedes may be run with much bigger problems on parallel processors). The large topographic scale between the bottom of the valley (at $1500 \mathrm{~m}$ amsl) and the surrounding hills (at 2600-2800 m) also created several computational problems. The high degree of scattering within the wave field reflected down from the free surface has lead to the errors generated at the absorbing boundary described in section 4.1. These errors are more pronounced due to the efficiently shaped lower boundary of the model that was selected as a compromise in the trade-off between accuracy and computational efficiency. 
A comparison of the results of the modelling in this study with recorded data reveals very little evidence of any correlation between the two. This is an alarming result; however, it should be noted that the modelling in this study was carried out in a rather blind fashion. Fourier spectra at the three stations of interest were not studied in detail prior to the development of the crosssection model. Rather it has been based solely on the assumed geological-geotechnical model of the valley.

We can, however, hypothesise as to why the modelled results are significantly different to the recorded data. At accelerograph station UEA, the comparison is reasonable, except that the fundamental resonance mode at $\sim 6 \mathrm{~Hz}$ predicted in the modelling is not evident in the Fourier spectral ratios calculated from recorded data. In fact the FSR of site UEA is less than unity for frequencies above $3.2 \mathrm{~Hz}$. This result may be due to the high frequencies being filtered out during the FSR calculation by an abundance of high frequency motion at station ESE compared to UEA.

At accelerograph station ISA, the recorded data shows a group of peaks of lower FSR and at significantly higher frequencies than that in the modelling result. Although an exact match in the magnitude (FSR) of these peaks might not be expected from twodimensional modelling, it would be hoped to be able to predict the frequency at which they occur. Because the site does not appear to have a locally complex threedimensional nature, an accurate one-dimensional model should be able to predict the approximate resonant frequencies. A closer inspection of shearwave velocity results at the ISA borehole reveals that the homogeneous approximation of the $30 \mathrm{~m}$ deep debris-flow layer (Qfs) is quite unrealistic and not overly representative of the measured data. While the top few metres are very soft, the material below 10 metres is much stiffer than is modelled. In addition, the residual soil below this may be much less weathered than is assumed due to its depth. The material properties adopted in the cross-sectional model, and shown in Table 1, are representative over the whole width of the Aburrá Valley rather than at each particular site. An analysis with more site-specific data would undoubtedly give a better approximation of the recorded results.

At accelerograph station EET there is a large discrepancy between the recorded and modelled Fourier spectral ratios. In many ways, this extreme lack of correlation is not a complete surprise. The topography at station EET is highly irregular in both horizontal orientations, and the two-dimensional model used (Figure 9) does not do justice to the site conditions. It seems most likely that the resonant frequency of $3.0 \mathrm{~Hz}$ seen here is a fundamental mode of vibration of the small knoll of artificial and debrisflow deposits on which EET is sited. There may also be some influence from the large water-storage tank close- by, and larger-scale multi-dimensional effects due to the surrounding debris-flow deposit and bedrock geometries.

Although few conclusions can be made as to seismic site response for specific locations within the Aburrá Valley, this study has been highly successful in the sense that the major contributors to seismic response have been identified. Two-dimensional modelling has shown the role, scale and influence of horizontal effects within the valley. The necessity to use highly accurate and site-specific data has been made evident for a valley with such an irregular and often thin covering of soil; such that there is perhaps a need for an even more detailed physical model of the nearsurface geology. Meanwhile, the fact that the real response of the soil as registered by the accelerograph network is significantly different to the results obtained in this study, points to the indispensable value of the recording instruments.

\subsection{CONCLUSIONS}

The seismic response of the Aburrá Valley has been modelled with both one- and two-dimensional finiteelement methods. The results have been compared both against each other in order to identify the dominant features of the valley that influence its response, and with weak motion data recorded at three different locations. The following conclusions have been made:

- There is some evidence of a two-dimensional whole-valley pattern of seismic response, yet its effect does not appear to be dominant or even particularly important to the response at any given site. Although highly variable in nature and depth, the soft soil covering within the valley appears to be too thin compared to the overall dimensions of the valley to produce a significant whole-valley response pattern.

- The response at a given site appears to be highly dependent on an intricate combination of onetwo- and even three-dimensional effects, which occur as a result of large- and small-scale features of the immediate and surrounding topography and near-surface soft soils. The most influential features are usually less than a few kilometres across.

- At many sites across the valley, one-dimensional modelling correctly predicts the frequency of peaks within the Fourier spectrum, yet does not accurately define the value of FSR to be expected. The FSR values are often influenced by weak twodimensional patterns of resonance set up within poorly-constrained soft units such as debris-flows. 
- At sites that are very multi-dimensional on a local scale - such as at accelerograph station EET or within the alluvial dip in the centre of the valley strong horizontal resonant modes may be present. Here, one-dimensional modelling is unlikely to predict the correct resonant peaks.

- Two-dimensional modelling gives a strong indication of whether or not the influence of horizontal effects will be significant in changing the amplitude (and perhaps frequency) of the peaks identified in a one-dimensional analysis.

- Two-dimensional modelling is generally not an adequate characterisation for much of the Aburrá Valley. The extent to which soil deposits and topographic features in the cross-valley orientation influence the response leads to an expectation of the same in the long-valley direction, where the geology and topography are also highly irregular. At some locations, however - such as the alluvial dip in the centre of the model where the longvalley geometry is more uniform - twodimensional modelling is likely to be sufficient to define the resonant response.

- The results from the modelling in this study show poor correlation with recorded data at three different locations. This outcome points toward the need of a more detailed model of geometry and material properties to correctly predict even the elastic response at a given site. It also points toward the indispensable value of the Medellín accelerograph network.

\section{ACKNOWLEDGEMENTS}

Thanks to Luis Andrés Palacio (Ingeneria Civil, Universidad EAFIT, Medellin, Colombia), Gloria Maria Estrada (Geotechnical Engineer, Integrál SA, Medellin, Colombia) and Diego Rondón (Consulting Geologist, Medellín, Colombia) for both logistical and technical aspects of this study. Thanks also to Jacobo Beilak and Jifeng $\mathrm{Xu}$ (Civil and Env. Engineering, Carnegie Mellon University, Pittsburgh, PA.) for their support with the Archimedes computation; and to Rob Davis and John Berrill (Civil Engineering, University of Canterbury) for their reviews and comments. This work was funded by the Earthquake Commission of New Zealand (EQC), the New Zealand Society for Earthquake Engineering, and the University of Canterbury. The research was made possible with information collected during a short trip to Medellín, Colombia by the first author between 14 and 30 August 1999. Subsequent numerical modelling was carried out between September 1999 and February 2000 at the University of Canterbury.

\section{REFERENCES}

Adams, B.M. (2000) Basin-Edge Effects from SH Wave Modelling with reference to the Lower Hutt Valley, New Zealand. PhD Thesis, Dept. Civil Eng., University of Canterbury, October 2000. 270p.

Adams, B.M.; Berrill, J.B.; Davis, R.0. and Taber, J.J. (2000) Modeling Site Effects in the Lower Hutt Valley, New Zealand. Proceedings of the $12^{\text {th }}$ World Conference on Earthquake Engineering, Auckland, New Zealand. Paper no. 2694.

Bao, H.; Bielak, J.; Ghattas, O.; Kallivokas, LF.; O'Hallaron, DR.; Shewchuk, JR. and Xu, J. (1998) Large-Scale Simulation of Elastic Wave Propagation in Heterogeneous Media on Parallel Computers. Computer Methods in Applied Mechanics and Engineering. 152: 85-102. Elsevier Science, S.A.

Bard, P.Y. and Bouchon, M. (1985) The TwoDimensional Resonance of Sediment-Filled Valleys. Bull. Seism. Soc. Am. 75: 519-541.

Bielak, J. and Christiano, P. (1984) On the Effective Seismic Input for Nonlinear Soil-Structure Interaction Systems. Earthq. Eng. and Struct. Dyn. 12: $107-119$.

Bielak, J.; Xu, J. and Ghattas, O. (1999) Earthquake Ground Motion and Structural Response in Alluvial Valleys. J. Geotechnical and Geoenvironmental Engineering, ASCE. 125 (5): 413-423.

Borcherdt, R.D. (1970) Effects of Local Geology on Ground Motion near San Fransisco Bay. Bull. Seism. Soc. Am. 60 (1): 29-61.

Cremonini, M.G.; Christiano, P. and Beilak, J. (1988) Implementation of Effective Seismic Input for Soil-Structure Interaction Systems. Earthquake Engr. Struct. Dyn. 16: 615-625.

Davis, R. (1995) Effects of Weathering on Site Response. Earthq. Eng. and Struct. Dyn. 24: 301 309.

Davis, R. and Hunt, B. (1994) Amplification of Vertically Propagating SH Waves by Multiple Layers of Gibson Soils. Intl. J. for Numerical and Analytical Methods in Geomechanics. 18: 205212.

Escallón, J. and Alarcón, A. (2000) The January 25 1999 Earthquake in the Coffee Growing Region of Colombia - Tectonic and Seismological Aspects. Proceedings of the $12^{\text {th }}$ World Conference on 
Earthquake Engineering, Auckland, New Zealand. Paper No. 2805.

Farbiarz, J.; Jaramillo, J.D. and Villarraga, M.R. (2000) Microzonation of the City of Medellín. Proceedings of the $12^{\text {th }}$ World Conference on Earthquake Engineering, Auckland, New Zealand. Paper No. 2710.

Groupo de Sismología de Medellín (1999) Instrumentación y Microzonificación Sísmica del Área Urbana de Medellín. Informe para SIMPAD (Sistema Municipal de Prevención y Atención de Desastres) y Municipio de Medellín Secretaria Privada (in Spanish).

Groupo de Sismología de Medellín (1997) Instrumentación y Microzonificación Sísmica del Área Urbana de la Cuidad de Medellín. Informe Final (Versión detallado) con Adición CSA121 de Octubre 1998. Contracto C112 para SIMPAD (in Spanish).

Hincapié, J.E.; Osorio, R.; Pineda, C.M. and Urrea D.P. (1993) Hacia una Zonación SismoGeotécnica de Medellín. Programa de Prevención Sísmica para Medellín, Segunda Etapa: Parte II. PNUD, Alcaldía de Medellin. Universidad EAFIT (in Spanish).

Hisada, Y.; Bao, H.; Bielak, J.; Ghattas, O. and O'Hallaron, D.R. (1998) Simulations of LongPeriod Ground Motions during the 1995 Hyogoken-Nanbu (Kobe) Earthquake using 3D Finite Element Method. Proc. 2nd Intl. Symposium on the Effect of Surface Geology on Seismic Ground Motion, Yokohama, Japan. Dec. 1-3, 1998.

Jaramillo, J.D. and Ortega, D.C. (1993) Estudio del Riesgo Sísmico de Medellín. Programa de Prevención Sísmica para Medellín, Segunda Etapa: Parte III. PNUD, Alcaldía de Medellin. Universidad EAFIT (in Spanish).

Kellogg, J.N. and Dixon, T.H. (1990) Central and South American GPS Geodesy - CASA UNO. Geophysical Research Letters. 17 (3): 195-198.

Restrepo, J.I. and Cowan, H.A. (2000) The "Eje Cafetero" Earthquake, Colombia of January 25 1999. Bull. N.Z. Natl. Soc. Earthquake Eng. 33 (1): 1-30.

Ricker, N. (1940) The Form and Nature of seismic Wavelets and the Structure of Seismograms. Geophysics. 5: 348-366.

Shewchuck, J.R. (1996) Triangle: Engineering a 2D Quality Mesh Generator and Delaunay Triangulator. First Workshop on Applied Computational Geometry (Philidelphia, PA.). pp 124-133, ACM, May 1996.

Velásquez, E. and Jaramillo, J.D. (1993) Estudio de la Amenaza Sísmica de Medellín. Programa de Prevención Sísmica para Medellín, Segunda Etapa: Parte I. PNUD, Alcaldía de Medellin. Universidad EAFIT (in Spanish). 